\title{
GOBIERNO EN FUNCIONES Y DESPACHO ORDINARIO \\ DE LOS ASUNTOS PÚBLICOS (LAS SSTS DE 20 DE SEPTIEMBRE Y 2 DE DICIEMBRE DE 2005)
}

\author{
JOAQUÍN BRAGE CAMAZANO \\ Universidad Complutense de Madrid \\ FERNANDO REVIRIEGO PICÓN \\ Universidad Nacional de Educación a Distancia
}

\author{
SUMARIO \\ I. Introducción.
II. El despacho ordinario de los asuntos pú- blicos y la diferente naturaleza de los su- \\ puestos de cese. \\ III. El indulto y la extradición en nuestro or- \\ denamiento. \\ IV. Dos resoluciones judiciales contradicto- \\ rias.
}

\section{INTRODUCCIÓN}

La reflexión en torno a la concepción teórica y a la actividad de un Gobierno en prorrogatio de funciones se ve estimulada en situaciones conflictivas, derivadas tanto de procesos electorales de lenta resolución como de cambios de orientación política que acentúan los recelos sobre la actuación de estos gobiernos en trance de cesar. En este marco, sin temor a equivocarnos podemos afirmar que el supuesto más llamativo en los últimos tiempos lo hemos tenido, en el ámbito autonómico, con ocasión del Gobierno que permaneció en funciones en la Comunidad de Madrid tras las elecciones mayo de 2003 en donde, recordemos, su Presidente simultaneó tal cargo con el de Alcalde durante casi seis meses en una más que dudosa compatibilidad; más atrás en el tiempo, quién no recuerda la permanencia en funciones en el Gobierno de Cantabria, durante nueve meses, de un Presidente que había sido condenado a penas de 
prisión e inhabilitación para cargo público por el Tribunal Superior de Justicia de dicha Comunidad. En otro orden de cosas, más recientemente, la permanencia en funciones del Gobierno de la Xunta de Galicia tras las últimas elecciones de mayo de 2005 sirvió de detonante para que se formularan diversas propuestas de una regulación legal y estatutaria de las limitaciones a un Gobierno en este estado; recordemos que es ésta una de las pocas Comunidades Autónomas en donde no se recoge todavía limitación expresa alguna a la actuación de un Gobierno cesante, ya que la práctica totalidad de las mismas (únicamente escapan a esta tendencia, junto a aquella, las Comunidades Autónomas de Canarias, Cataluña y Valencia, al no contemplar limitación alguna respecto de un Gobierno este estado ni en sus Estatutos ni en sus leyes de gobierno $^{1}$ ) regulan de forma detallada la posición y las restricciones en el ámbito competencial de los Gobiernos en trance de cesar ${ }^{2}$.

Pues bien, situaciones como estas han dado lugar a dos recientes e interesantes sentencias de la Sala de lo Contencioso-Administrativo del Tribunal Supremo (SSTS de 20 de septiembre - Sección 6. ${ }^{\text {a }}$ - y 2 de diciembre de 2005 -Pleno-), luego veremos si contradictorias, en las que se examina la legalidad (e, indirectamente, la constitucionalidad) de sendas decisiones tomadas por el Gobierno que permaneció en funciones tras las últimas elecciones generales de marzo de 2004, sentencias que precisamente van a ser objeto central de este comentario.

En virtud de la primera de esas sentencias, el Tribunal Supremo ha anulado la decisión de aquel Gobierno en funciones de conceder la extradición de una ciudadana británica a las autoridades italianas, al entender que ello excedería con claridad del "despacho ordinario de los asuntos públicos", criterio paramétrico básico empleado por la Ley 50/1997, de 27 de noviembre, del Gobierno, en orden a delimitar la actuación de los gobiernos cesantes (STS de 20 de septiembre de 2005).

Por su parte, justamente por entender lo contrario, se desestima en la segunda sentencia el recurso interpuesto frente a otra decisión del mismo Gobierno en funciones, la denegación de una petición de indulto; en este segundo caso, el Tribunal Supremo entendió que la decisión adoptada se encontraba cobijada por el referido manto (STS de 2 de diciembre de 2005).

1 Se ha presentado recientemente en el Parlamento de Andalucía un proyecto de ley de gobierno que procede a regular diversas limitaciones a un Gobierno en este estado ( $B O P A$ de 5 de abril de 2006); asimismo, en Galicia se está preparando una reforma con directrices limitadoras que fue comprometida por el actual Presidente de la Xunta ante el Parlamento (DSPG de 14 de septiembre de 2005).

2 Se han establecido, así, limitaciones de todo tipo en su ámbito de acción, ya de carácter específico (como la imposible presentación de proyectos de ley, ejercicio de delegaciones legislativas, aprobación depresupuestos, nombramiento de altos cargos de la Administración, aprobación de convenios o acuerdos de colaboración y cooperación con el Estado y otras Administraciones Públicas, etc), ya de carácter genérico (como la reconducción de la actividad de un Gobierno en dicho estado a supuestos de ordinaria administración o urgencia, e incluso a un difuso interés general); la regulación más reglamentista la encontraríamos en la Ley de Gobierno de Extremadura. 
Previo al estudio de estas resoluciones de nuestro Tribunal Supremo, que giran en torno al ámbito de competencias de un Gobierno en funciones, parece preciso recordar que la única previsión de nuestro Constituyente respecto de éste fue la contenida en el actual artículo $101 \mathrm{CE}$, en donde, tras la determinación de los diferentes supuestos de cese del órgano gubernamental, se señala que el Gobierno cesante continuará en funciones hasta la toma de posesión del nuevo Gobierno. Ninguna otra determinación adicional estableció respecto de dicha continuidad, provisional aunque temporalmente indeterminada, $\mathrm{y}$ que de hecho puede llegar a prolongarse durante varios meses.

Así pues, el único precepto constitucional que regula esta figura se limita a estipular que la actividad del Gobierno cesante debe continuar hasta el acaecimiento de otro suceso, que será la toma de posesión de los nuevos titulares del mismo; este acontecimiento ha de llegar, mas se desconoce el momento exacto en que el mismo se verificará (certus an incertus quando): por ello, la actuación del Gobierno en funciones es siempre una actuación sujeta a término, y no a mera condición, aunque lo sea "a término incierto", y en todo caso sólo por el tiempo preciso en cada caso para facilitar el normal desarrollo del proceso de formación del nuevo Gobierno y el traspaso de poderes a éste, idea recogida expresamente por la Ley del Gobierno y que parece poco controvertible en esta formulación tan abstracta.

Hasta la aprobación de esta Ley, la escueta regulación constitucional dio pie a diferentes interpretaciones sobre tal permanencia y las implicaciones que en su actuación se determinarían, así como sobre la posibilidad o no del establecimiento de limitaciones competenciales durante esos períodos, interpretaciones que hoy todavía colean ${ }^{3}$, al igual que ocurre en otros países. Y lo cierto es que la literalidad del art. 101.2 CE, al igual que ocurre con el artículo 69 de la Ley Fundamental de Bonn ${ }^{4}$, no dice nada todavía sobre si ese Gobier-

3 Véase, a título de ejemplo, antes de la aprobación de la Ley del Gobierno, los trabajos de AGUIAR DE LUQUE, L., "La posición del gobierno cesante o en funciones en el ordenamiento constitucional español, El Parlamento y sus transformaciones actuales, GARRORENA, A., (Ed.), Asamblea Regional de Murcia / Tecnos, Madrid, 1990, pp. 261 a 270; REVENGA, M., «El Gobierno en funciones", Gobierno y Administración en la Constitución (Vol. II), VVAA, Dirección General del Servicio Jurídico del Estado, 1988, pp. 1501 a 1523; o SATRÚSTEGUI, M., "Artículo 101. El cese del Gobierno y el Gobierno cesante,, Comentarios a las Leyes Politicas, ALZAGA, O., (Dir.), Editorial Revista de Derecho Privado, Madrid, 1985, pp. 213 a 236.

4 En Alemania, el art. 69 de la Ley Fundamental establece que "A requerimiento del Presidente Federal, el Canciller Federal está obligado a seguir dirigiendo los asuntos hasta el nombramiento del sucesor, y a requerimiento del Canciller o del Presidente Federal, la misma obligación recae sobre un ministro federal.. En la doctrina este tema apenas ha sido abordado en profundidad; el trabajo relativamente más amplio sigue siendo el de R. LUTZ (Die Geschäftsregierung nach dem Grundgesetz, Duncker und Humblot, Berlín, 1969); otro autor que ha tratado el tema ha sido DREHER, autor de prácticamente la única monografía sobre el Gobierno cesante durante la época de Weimar, quien ya mucho después, en 1982, se refería a cómo se hallaba bastante solo en la doctrina en su posicionamiento, entendiendo DREHER, que este Gobierno, por su propia naturaleza y a partir también de la regulación constitucional, no podía tener las mismas funciones que uno apoyado en la confianza parlamentaria, sino sólo la competencia para abordar los asuntos corrientes y urgentes, pues lo que exceda de eso no podría llevarlo a cabo ni el Gobierno en funciones ni nin- 
no ha de tener, o no, las mismas competencias que un Gobierno que no esté en trance de cesar.

Sin embargo, no cabe desconocer que a favor de esas limitaciones existían razones de peso, que podríamos concretar someramente - en una interpretación de conjunto, teleológica y sistemática del texto constitucional- en las razones ligadas al propio concepto y naturaleza (figura transitoria, excepcional y de necesidad), posición (carencia, y falta de necesidad, de una legitimación parlamentaria, con legitimación directa excepcional ope constitutionis) y fin (el traspaso de poderes) de un Gobierno en funciones, y carente, por tanto, de todo respaldo parlamentario. Sea como sea, lo que es claro es que no resulta hoy aplicable entre nosotros la imagen dibujada por Tocqueville respecto de los Gobiernos en funciones: "En el mismo momento, es cierto, en que la fortuna ha decidido, ese ardor se disipa, todo se calma y el río, un momento desdordado, vuelve apaciblemente a su cauce. Pero, ¿no es sorprendente que la tormenta haya podido desencadenarse?, 5 .

Pero tampoco cabe desconocer, por otro lado, que en contra de ello, o cuando menos en contra de una restricción severa de sus competencias, juega el principio de la necesaria continuidad del funcionamiento de la maquinaria estatal, y en concreto de uno de sus poderes más activos e indisponibles, como es el Ejecutivo. Principio que parece oponerse tanto más a una restricción de las competencias de dicho Gobierno precisamente en la situación en que su legitimación tiende a ser menor, es decir, cuando la situación de interinidad gubernamental se prolonga en el tiempo más de lo inicialmente considerado como razonable, pues, considerado desde ese punto de vista de la necesaria continuidad de las funciones estatales, nos parece claro que cuanto más larga se haga esa interinidad, más difícil será justificar una parálisis gubernamental, aunque sea sólo parcial o fragmentaria, y por ello, más peso adquieren las razones contrarias a una restricción de las competencias de ese Gobierno que es-

gún otro órgano no responsable ante el Parlamento ("Geschäftsführende Regierungen", Neue Juritische Wochenschrift, 1982, p. 2808), sino que son asuntos que deben esperar hasta que se constituya un nuevo Gobierno "normal". La posición dominante hoy en día en Alemania parece seguir siendo la de que el Gobierno en este estado tiene las mismas competencias que uno normal (respecto de la Constitución de Weimar, el Tribunal del Estado para el Imperio Alemán llegó a afirmar incluso que este Gobierno quedaba "obligado a hacer todo lo que exija el bien del Estado" y la prudencia en el ejercicio de sus competencias se vio por autores como ANSCHÜTZ o STIER-SOMLO simplemente como una "cuestión de tacto político"). Cfr. STERN, K., Das Staatsrecht der Bundesrepublik Deutschland, Band II (Staatsorgane, Staatsfunktionen, Finanz - und Haushaltsverfassung, Notstandverfassung), C.H. Beck, Múnich, 1980, p. 297.

5 TOCQueville, A., La democracia en América, FCE, México, 1994, pp. 130 y 136. TOQUEVILLE afirma que, aun cuando se regulase la materia de forma que "la sede del poder ejecutivo no permanezca, por decirlo así, vacante nunca", al aproximarse las elecciones "la nación entera cae en un estado febril" y, además, "cualquier cosa que se haga, el vacío existe en los espíritus a despecho de los esfuerzos del legislador", recordando las palabras de Jefferson, seis meses antes de las elecciones, de que no tomaba parte en los asuntos más que expresando su opinión pues le parecía justo dejar a su sucesor "la iniciativa de las medidas cuya ejecución tendrá que seguir, soportando su responsabilidad". 
tará en funciones, pero que de hecho tiene en sus manos, durante un período más o menos prolongado, el timón de una Nación necesitada de ser pilotada y que no puede permanecer mucho tiempo sin un rumbo político definido.

Sea como sea, en el marco de esta indeterminación constitucional, la Ley de Gobierno optó por una interpretación que restringía las competencias del Gobierno en funciones, y estableció una regulación muy detallada y hasta un tanto reglamentista sobre sus competencias. Esto llevó a algunos autores a manifestar su opinión crítica respecto de la misma y ello tanto por sus inconvenientes funcionales como por «implicar una tendencia a sustraer espacios de libertad de la vida política", al entender que con ello no hacía sino extenderse "un velo de desconfianza sobre el Gobierno, olvidando su necesidad y su legitimidad democrática", a lo que se uniría que "el hecho de constituir un caso único en el Derecho comparado democrático es un buen indicio de esta extrañeza al genuino sistema constitucional" 6 .

De esta manera, junto a limitaciones específicas de competencias tanto del Gobierno (la aprobación del Proyecto de Ley de los Presupuestos Generales del Estado y la presentación de proyectos de ley a cualquiera de las Cámaras) como de su Presidente (la proposición de disolución de alguna de las Cámaras o de las Cortes Generales y de la convocatoria de un referéndum consultivo, así como el planteamiento de la cuestión de confianza), se estableció la acotación genérica de su actividad con base en tres conceptos jurídicos indeterminados: el despacho ordinario de los asuntos públicos — antes referido_-, la urgencia y el interés general. Otra limitación adicional específica habría quedado prescrita exclusivamente con relación a un específico supuesto de cese; así habría sucedido, en concreto, con las delegaciones legislativas, que quedarían en suspenso en los casos en que el Gobierno se encontrare en funciones por la celebración de elecciones generales, previsión también polémica. La máxima latina sede vacante nibil innovetur cobraría aquí completo significado al amparo de una minuciosa reglamentación.

No corresponde ahora valorar todas y cada una de las diferentes limitaciones pergeñadas en aquel cuerpo legal (alguna de las cuales podría llegar a provocar la desnaturalización de los límites genéricos propios de la perma-

6 Véase, SANTAOLALlA LÓPEZ, F., "Artículo 101", Comentarios a la Constitución, GARRIDO FALLA, F., (Ed.), Cívitas, Madrid, 2001, p. 1575. ÁLVAREZ CONDE, aunque desde una perspectiva favorable al criterio de la Ley, apuntará que resulta "significativo que ninguna de las democracias clásicas (Reino Unido, Bélgica, Holanda, Luxemburgo, Suecia y Dinamarca) han creído necesario someter a ordenación positiva esta materia", "El Gobierno en funciones", Documentación

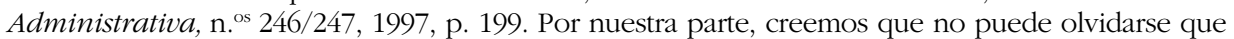
el Gobierno es un órgano constitucional, que representa además a uno de los tres poderes clásicos del Estado nada menos, y esa naturaleza de órgano constitucional hace problemática la existencia misma de la Ley del Gobierno, ya que "normalmente los órganos constitucionales ven reguladas en la Ley Fundamental su constitución, organización, competencias y procedimiento y en todo lo demás se les da autonomía sin necesidad de la interpositio legislatoris" (BRAGE CAMAZANO, J., "Estudio introductorio: El Tribunal Constitucional Federal y la jurisdicción constitucional en Alemania, con particular referencia al pensamiento de Peter Häberle y Konrad Hesse", HESSE, K., HÄBERLE, P., Estudios sobre la jurisdicción constitucional, traducción de J. BRAGE, Porrúa, México, 2005). 
nencia en funciones $^{7}$ ); ni siquiera apuntar las dudas de constitucionalidad que la previsión de las mismas suscitó en un sector de la doctrina ${ }^{8}$, y aún sigue suscitando 9 . Tampoco nos referiremos a la cuestión de si algunas de tales limitaciones pudieran derivar implícitamente del texto constitucional como exigencias de este, y no como mera posibilidad del legislador. Todo ello escaparía al cometido de estas líneas, habiendo sido objeto, por otra parte, de diferentes estudios de un tiempo a esta parte, a los cuales no podemos sino remitimos en este momento ${ }^{10}$.

Nuestras reflexiones, al hilo del comentario de las sentencias antes referidas, quedarán constreñidas a esa delimitación genérica ${ }^{11}$ de la actividad del Go-

7 Sobre la apelación al "interés general" véase PAREJO, L., "La regulación del Gobierno y la Administración; continuidad y discontinuidad en la política de desarrollo constitucional en la materia", Documentación Administrativa, n. ${ }^{\circ}$ 246/247, 1997, pp. 38/39.

8 PÉREZ TREMPS, por ejemplo, apuntó — respecto de las previsiones del proyecto que continuarían recogidas en el texto definitivo- su dudosa constitucionalidad por su propia cobertura, o, mejor, ausencia de cobertura, señalando que "no existe en la Norma Fundamental ninguna base normativa que permita restringir legalmente las competencias que la propia Constitución reconoce al Gobierno; es más, la figura del Gobierno cesante está expresamente recogida en el artículo 101.2 CE para señalar que sigue en funciones, pero sin recortar o limitar el alcance de esas funciones", "Composición, organización y estatuto de los miembros del Gobierno: apostillas al Proyecto de Ley del Gobierno", Documentación Administrativa, n. ${ }^{\circ}$ 246/247, 1997, p. 111. SANTAOLALLA, por su parte, apuntará que "si no hay límites constitucionales no puede haberlos por vía de ley ordinaria. La Ley del Gobierno comete así un exceso de regulación, que se hace inconstitucional", "Artículo 101", cit., p. 1576.

9 Un claro ejemplo se pone de manifiesto en el detallado voto particular de E. ESPÍN a la STS de 2 de diciembre de 2005, en donde, tras apuntar las serias dudas de constitucionalidad que las previsiones legales le plantean, apuntaba que hubiera sido preciso el planteamiento de una cuestión de inconstitucionalidad; idea a la que añadirá lo siguiente: "me parece evidente que en lo que respecta a las potestades que derivan directamente del texto constitucional y que se corresponden con las funciones de los poderes del Estado, el legislador sólo puede imponer aquellos límites que deriven de la propia Norma constitucional, sea explícita o implícitamente. Lo contrario es asumir indebidamente una posición cuasi constituyente y afectar de manera irremediable al equilibrio de poderes y al adecuado ejercicio por éstos de sus funciones constitucionales tal y como queda diseñado por la Constitución; la limitación que el legislador ha impuesto a la capacidad de actuar del Gobierno en funciones en el artículo 21.3 de la Ley 50/1997 es dudosamente compatible con la Constitución, ya que ésta no restringe dicha capacidad deactuar de manera genérica ni explícita ni implícitamente, y dicha limitación sustrae al ámbito de la política del sistema democrático parlamentario toda una serie de decisiones políticas y las somete indebidamente al juicio de los tribunales".

10 Estudios detallados sobre dichas limitaciones pueden encontrarse en: SATRÚSTEGUI, M., "El cese del Gobierno y el Gobierno cesante", Comentarios a la Constitución Española de 1978, Tomo VIII, ALZAGA, O., (Ed.), Editorial Revista de Derecho Privado, Madrid, 1998, pp. 359 a 366; REVIRIEGO PICÓN, F., El Gobierno cesante o en funciones en el ordenamiento constitucional español, BOE-Universidad Carlos III, Madrid, 2003, pp. 199 a 281; GUILLÉN LÓPEZ, E., El cese del gobierno y el gobierno en funciones en el ordenamiento constitucional español, Instituto Andaluz de Administración Pública, Sevilla, 2002, pp. 61 a 117; GONZÁLEZ ALONSO, A., "El Gobierno en funciones", El Gobierno. Problemas constitucionales, ARAGÓN REYES, M., GÓMEZ MONTORO, A.J., CEPC, Madrid, 2005, pp. 544/557; NARANJO DE LA CRUZ, R., "El ámbito funcional del Gobierno cesante", Cuadernos Constitucionales de la Cátedra Fadrique Furió Cerol, n. ${ }^{\circ} 36 / 37,2001$, pp. 23/48.

11 Estas previsiones son una de las escasas diferencias de la Ley del 97 con el proyecto de Ley del 95 del que sin duda es directamente tributaria aquella, BOCG, CD V Legislatura. Serie A. 6 de noviembre de1995. N. ${ }^{\circ} 141-1$. 
bierno cesante y a la cuestión de si las dos decisiones discutidas, y objeto de enjuiciamiento por el Tribunal Supremo, estarían o no cobijadas bajo el manto de actuación de un Gobierno en ese estado conforme a las previsiones legales mencionadas.

\section{EL DESPACHO ORDINARIO DE LOS ASUNTOS PÚBLICOS Y LA DIFERENTE NATURALEZA DE LOS SUPUESTOS DE CESE}

El despacho ordinario de los asuntos públicos es, como hemos apuntado, uno de los tres conceptos jurídicos indeterminados con los que el legislador quiso acotar y delimitar la actuación de un Gobierno cesante ${ }^{12}$. Ello no es totalmente novedoso, pues ya la Constitución prusiana de 1920 preveía que un Gobierno en este estado tendría a su cargo los "asuntos corrientes", previsión que, al criterio del Tribunal del Estado de aquella época, no derivaría en limitación alguna.

Sea como fuere, es preciso decir que el rasgo del despacho ordinario de los asuntos públicos como elemento de delimitación de la actividad legítima del Gobierno en funciones, asumido por nuestra Ley del Gobierno, encajaba perfectamente, mutatis mutandis, en la concepción doctrinal dominante respecto de la actuación de un Gobierno en este estado, que, en ausencia de ley, acostumbraba a reconducir su acción a los asuntos corrientes, a la ordinaria administración, etc., dentro de una idea genérica de autorrestricción y de abstención ante la duda ${ }^{13}$. Pero aun siendo esto así, una cosa es que los sucesivos Gobiernos, cuando se hallen en funciones, restrinjan, o deban restringir según la doctrina predominante, su actividad por razones de Derecho constitucional y otra muy distinta, como destacara Anschütz, es que lo hagan, o deban hacerlo, por puras razones de tacto político. Y es claro que la Ley del Gobierno lo que estableció, como no podía ser de otro modo, son criterios que pretendían ser jurídicamente vinculantes en la fijación de unos contornos a la actividad lícita de un Gobierno en funciones. Desde esta perspectiva de su pretensión de

12 En el ámbito autonómico, la terminología utilizada en este punto es dispar; así, algunas leyes de gobierno optan por servirse de esa misma expresión, "despacho ordinario de los asuntos públicos", mientras que otras emplean fórmulas alternativas, como "funcionamiento normal de los servicios públicos", "normal funcionamiento de la Administración" o "gestión ordinaria".

13 M. SATRÚSTEGUI, en un trabajo en el que anticipaba la práctica totalidad de previsiones que una década más tarde recogería la Ley del Gobierno, apuntaba también como criterios generales a aplicar en estos períodos que "cuando surjan dudas sobre si una determinada decisión se mantiene en el ámbito de la conservación y tutela de los intereses generales, o si, por el contrario se encuadra dentro de una política discrecional de ordenación del futuro, el Gobierno cesante debe abstenerse de actuar", y que "si por razones de urgencia el Gobierno cesante se entiende, sin embargo, legitimado para actuar, en los casos dudosos antes mencionados o incluso en otros en que la decisión implique una valoración todavía más marcadamente política, su línea de conducta debe reflejarse en actos que prejuzguen lo menos posible la solución final del problema", "Artículo 101. El cese del Gobierno y el Gobierno cesante", Comentarios a las Leyes Políticas, cit., pp. $235 / 236$. 
vinculatoriedad jurídica estricta debemos analizar el concepto de "despacho ordinario" de los asuntos. Ello nos conduce, ya de entrada, a dos obstáculos con que la tarea tropieza desde su comienzo mismo: la necesidad de una integración casuística del concepto y las densas dosis de politicidad que pueden llegar a darse de modo no infrecuente.

Sobre lo primero, hay que empezar por decir que el análisis de conceptos similares, vinculados a esta actividad del Gobierno cesante, se había emprendido por la doctrina italiana y alemana - también francesa, aunque acotado a un período muy específico- desde mucho tiempo atrás, por más que existirían ciertas diferencias en las que ahora no entraremos, y si bien es claro que no existen "asuntos corrientes" u ordinarios por su misma naturaleza ${ }^{14}$-al ser aquellos que correspondan a la "marcha ordinaria de la vida" ${ }^{15}$-, sino que lo que en un momento puede ser calificado como tal, cabe considerar que excede de tal carácter en otro momento diferenciado, o en otras circunstancias (no sólo temporales), ello no torna justificada la crítica de una disolución del concepto en cuestión en una casuística imprecisa y generadora de una enorme inseguridad jurídica, sino que simplemente implica que el preciso alcance concreto de este concepto sólo podrá fijarse con relación a cada caso particular, pero ello, desde nuestro punto de vista, no impide, sino que más bien presupone, como luego veremos, una cierta generalización de criterios a partir del momento en que exista alguna jurisprudencia consolidada, y precisamente la sentencia de 2 de diciembre de 2005 que luego comentaremos es una buena muestra de hasta qué punto ello es así.

En cuanto a lo segundo, tampoco cabe negar que esa jurisprudencia va a venir necesariamente referida a decisiones adoptadas, en ciertas ocasiones, en un campo minado de apreciaciones políticas ${ }^{16}$. De ello resulta la evidente dificultad interpretativa y aplicativa de estos conceptos, nada nuevo en el ámbito del Derecho constitucional, por otro lado ${ }^{17}$, sino más bien su caldo de cultivo natural.

14 BOUYSSOU, F., "L`introuvable notion d’affaires courantes. L`activité des gouvernements démissionnaires sous la Quatrième République", Revue Française du Science Politique, (XX), n. ${ }^{\circ} 4$, 1970 , p. 669.

15 Esta sería la expresión utilizada por el Consejero de Estado francés M. LACHAZE al hilo de la conocida resolución de 1952 de dicho Consejo sobre el Syndicat régional des quotidiens d'Algérie, "L'expedition des affaires courantes en période de crise ministérielle", Recueil Dalloz, Chronique, 1952, pp. 66.

16 GALIZIA, M., "Crisis di gabinetto", Enciclopedia del Diritto, Giuffrè, Vol. XI, 1962, p. 392.

17 Similar problemática a la anterior, aunque en diferente medida, acontecería respecto de los otros conceptos utilizados por la Ley en orden a esa acotación genérica: urgencia e interés general. Este último concepto, como apuntó acertadamente PAREJO, vino en diluir "toda frontera jurídicamente discernible con precisión entre el Gobierno normal y actuante en funciones" en tanto que "razones de interés general suficientes debe haber siempre en la acción y decisión de uno y otro", por lo que hubiera resultado preferible articular un concepto ya acuñado en nuestra Norma suprema: la "extraordinaria y urgente necesidad"; se habrían "desnaturalizado" así los límites genéricos propios de la permanencia en funciones, de la prorogatio gubernamental. "La regulación del Gobierno y la Administración: continuidad y discontinuidad en la política de desarrollo constitucional en la materia", Documentación Administrativa n. ${ }^{\circ} 246 / 247,1997$, p. 39. 
El «despacho ordinario de los asuntos públicos» es un concepto jurídico indeterminado empleado por la Ley al que hay que tratar de dotar de unos perfiles lo más nítidos y precisos posibles. La sentencia de 2 de diciembre citada puede considerarse como un primer y significativo esfuerzo pretoriano en esa línea. Esta sentencia aplica la técnica de los conceptos jurídicos indeterminados para la fijación de un sentido más o menos preciso a esa expresión, si bien, como es natural y atinado, analiza la cuestión no desde un punto de vista puramente abstracto, como sería propio de un (muy ambicioso) trabajo académico, sino que lo hace sin perder de vista en ningún momento el caso particular sometido a enjuiciamiento, y en función del mismo, aunque sus consideraciones nos permiten fijar por aproximación los contornos de dicho concepto en unos términos abstractos.

Desde luego, nos parece claro, para empezar, que no es posible aquí, como algunos han apuntado, tratar de hacer un paralelismo respecto de los términos "despacho de asuntos" o "despacho de los expedientes" que podemos encontrar en la Ley de Régimen Jurídico y del Procedimiento Administrativo Común, en orden a derivar de ello que el concepto usado en la Ley del Gobierno se acotaría exclusivamente al ámbito puramente administrativo. Derivar del uso de esos términos tal conclusión parece improcedente, a la vista no solo de la tramitación parlamentaria de la Ley del Gobierno, sino asimismo del propio sentido de esta institución, y sobre todo, de la propia realidad social, a cuya luz hay que interpretar siempre cualquier norma jurídica: si al frente del Gobierno de la Nación quedara un Gobierno en funciones así concebido, ese "Gobierno" no sería ya ni siquiera un Gobierno para empezar, sino simplemente la cabeza de la Administración, pues lo que define constitucionalmente al Gobierno no es, en absoluto, sólo la dirección de la Administración civil y militar; sino también la circunstancia de que "dirige la política interior y exterior (..) y la defensa del Estado. Ejerce la función ejecutiva y la potestad reglamentaria de acuerdo con la Constitución y las leyes". Estaríamos, en tal concepción, ante un Gobierno en sentido formal tan capitidisminuido que, en la realidad de las cosas, sería un país sin Gobierno, y esto, como acertadamente apunta el Tribunal Supremo, es algo que no puede suceder ni por unas horas, y desde luego es algo que la Constitución no sólo no ha querido, sino que precisamente ha pretendido evitar a toda costa ese considerable vacío en el Poder Ejecutivo del Estado, y para ello justamente preceptúa que el Gobierno cesante "continúa en funciones hasta la toma de posesión del nuevo Gobierno", por contraste con el mayor "vacío de poder" que la Constitución sí permite, en mayor medida ya, respecto del Poder Legislativo como otro de los poderes estatales (aunque operando las Diputaciones permanentes, en todo caso, entretanto). Otra cosa es que el Gobierno, por hallarse en esta situación, pueda verse restringido en su labor de "dirección política" al "despacho ordinario", pero sin que, en nuestro criterio, este último concepto excluya la "dirección política" en sí misma, pues un Gobierno, en funciones o no, sin "dirección política" no sería ya un Gobierno, simplemente; a ello debe añadirse que, como dice $\operatorname{Stern}^{18}$, no puede admi-

18 STERN, K., Das Staatsrecht der Bundesrepublik Deutschland, cit., p. 297. 
tirse que la "dirección del Estado" quede vacante, por lo que la continuación de la tramitación o gestión de los asuntos del Gobierno es una necesidad y un deber, tanto más — añadiríamos nosotros - cuanto más se prolongue esa vacancia; y por otro lado, en fin, el deslinde entre las actuaciones puramente administrativas y las de dirección política es bien compleja, y en ocasiones sencillamente imposible, ya que, como dijera Friedrich, la política se forma a medida que se va ejecutando y se va ejecutando a medida que se forma. Esta concepción del "despacho ordinario" de los asuntos públicos, que reduce el mismo a los asuntos puramente administrativos, ha de quedar, así pues, completamente desechada.

Descartada una interpretación tan minimalista y reduccionista de la restricción legal del ámbito de actuación del Gobierno en funciones al "despacho ordinario de los asuntos públicos", son principalmente dos versiones —o, más bien, tendencias - contrapuestas las que pugnan por dar una imagen constitucionalmente adecuada de esta figura, y ambas, como luego veremos, están presentes en el seno del Tribunal Supremo:

Por un lado, una concepción estrecha, que considera, en síntesis, que el Gobierno en funciones no debe adoptar ninguna decisión que conlleve una valoración o actuación de contenido político.

Por otro lado, una concepción amplia, que admite que el Gobierno en funciones puede llevar a cabo actuaciones políticas, y considera que tiene vedadas únicamente las actuaciones que implican una nueva "dirección" u "orientación" política" o condicionan, comprometen o impiden la actuación del nuevo Gobierno llamado a sustituirle. Se plantea con ello, por un lado, la cuestión de qué se entiende por dirección política. La mejor doctrina ha señalado que la dirección política del Estado es algo que escapa a una definición conceptual concluyente, pues la manifestación de la dirección del Estado cambia, a pesar de ciertas constantes, en el tiempo, depende de ideas y energías políticas y de las personas que intervienen, y desde luego sus contornos jurídicos y su cualidad política lo harán del concreto ordenamiento constitucional ${ }^{19}$. Nuestro Tribunal Supremo, ante esta cuestión cuyo examen riguroso y abstracto produce verdadero vértigo doctrinal, ha sabido salir bastante airoso, como luego se verá, con un prudente análisis bastante apegado al caso, huyendo de apreciaciones excesivamente abstractas y completamente ajenas a su tarea jurisdiccional. Y, por otro lado, se plantea la problemática de qué ha entenderse por "nueva" orientación política y si este parámetro de lo novedoso es o no atinado y, aun siéndolo, si resulta suficiente.

Luego veremos el apoyo que cada una de estas concepciones ha encontrado en el seno del Tribunal Supremo hasta el momento actual. Por supuesto, sobra decir que estas son interpretaciones sobre lo que ha de entenderse por

19 SCHRÖDER, M. "\$67, Die Bereiche der Regierung und der Verwaltung", ISENSEE, J. KIRCHHOF, P., Handbuch des Staatsrechts der Bundesrepublik Deutschland, C. F. Müller, Heidelberg, 1988, pp. 501-502. 
"despacho ordinario" como actividad a que, según la Ley del Gobierno, ha de ceñirse el Gobierno en funciones, pero hay también que considerar que esa restricción legal, sea cual sea su significado, plantea dudas de constitucionalidad, cuando menos; y nosotros también dejamos ya apuntado cierto escepticismo acerca de la simple existencia de regulación legal, a falta de toda reserva expresa de ley en el texto constitucional, y tratándose como se trata de un órgano constitucional, y no de uno cualquiera sino precisamente de uno que encarna a uno de los tres poderes clásicos del Estado, y al más fuerte y materialmente imprescindible de ellos.

Sin entrar ahora a analizar cada una de estas concepciones básicas, ni las múltiples variantes que pueden presentar, sí que conviene ahora plantearse la cuestión de si, para interpretar el alcance de la actuación del Gobierno en funciones a partir de la Ley del Gobierno, ha de tener algún juego, como variable en la ecuación, el concreto supuesto de cese en el que nos encontremos en cada caso.

Técnicamente, todos los supuestos de permanencia en funciones serían idénticos. Aunque de diverso tenor, subyacente a todos se encontraría una quiebra del vínculo fiduciario. Acaecida una de las causas recogidas constitucionalmente (ya la ordinaria de la celebración de elecciones generales, ya los supuestos de pérdida de la confianza parlamentaria por los procedimientos articulados ad hoc, o la dimisión o fallecimiento del Presidente), el Gobierno debe permanecer en funciones hasta la toma de posesión del nuevo Gobierno.

Más allá de cuestiones evidentes relativas a la composición que huelga explicar, la actuación parece que debería revestir idéntico ámbito de acción sea cual fuere la hipótesis de cese. No obstante, algunos autores han defendido que la desaparición de aquél que personifica el vínculo fiduciario habilitador de la actuación gubernamental, provoca una suerte de "descabezamiento" del Gobierno que implica en todo caso la limitación de determinadas competencias que corresponden al Presidente en exclusividad, por ejemplo, la presentación de recursos de inconstitucionalidad ${ }^{20}$.

Sin embargo, es lo cierto que la única distinción entre supuestos (introducida por la Ley del Gobierno) haría referencia a la suspensión de las delegaciones legislativas otorgadas cuando el Gobierno se encontrare en tal estado por la celebración de elecciones generales. Por más que no nos interesa profundizar en ello, cabe apuntar que sobre esta limitación la doctrina no se habría manifestado de forma unánime, estando así dividida entre los que la consideran una limitación adecuada ${ }^{21}$, y los que no verían, por un lado, razones de Derecho Constitucional stricto sensu en la limitación, ni por otro, un criterio distin-

20 En ese sentido, JOVER, P., Temas de derecho constitucional, APARICIO, M. A., (Ed.), Barcelona, Cedecs, 1998, p. 435.

21 ARAGÓN REYES, M., "Estatuto de los miembros del Gobierno: Acceso y permanencia”, Estudios sobre el Gobierno. Seminario sobre el proyecto de Ley reguladora del Gobierno, BOE, Madrid, 1996, pp. 108 y 146, BAR CENDÓN, A., La disolución de las Cámaras Legislativas en el ordenamiento constitucional español, cit., p. 276; GONZÁlEZ ALONSO, A., "El Gobierno en funciones", cit., pp. 553 a 557. 
tivo entre la previsión de esta limitación para un supuesto de cese y no para el resto de hipótesis ${ }^{22}$; idea a la que habría que añadir para su reflexión, el dato de que no cabría configurar la legitimidad gubernamental como el elemento determinante de la misma ${ }^{23}$. Ante esta evidencia, quizá pudiéramos vernos tentados de recurrir al clásico Ubi lex non distinguit, nec nos distinguere debemus. Si ni el Constituyente ni tan siquiera el legislador (más allá de la concreta referencia apuntada) han establecido diferencia alguna entre los diversos supuestos de cese, no cabría introducirlo a estos efectos.

Mas lo cierto es que los supuestos de cese son muy dispares entre sí, incluso obedeciendo a una misma causa. Para ilustrar esta idea podríamos acudir a supuestos, todos reales, que nos resultarían ciertamente evidentes. Sin retrotraernos demasiado en el tiempo, nada tendrían que ver los dos últimos Gobiernos cesantes, que permanecieron en funciones tras las elecciones generales de 2000 y 2004. En aquéllas, el partido que apoyaba al Gobierno no sólo había mejorado los resultados de las anteriores elecciones que le habían llevado al poder, sino que había obtenido incluso la mayoría absoluta de los votos (pasó de contar con 146 escaños y un 42\% de los votos emitidos a obtener 183 y un 52\% de los sufragios), con lo que la continuidad (salvo extraño imprevisto - que en todo caso nunca debe descartarse ${ }^{24}$ _ $)$ estaba asegurada; al decir de la doctrina, se produciría así un ensanchamiento de su margen de maniobra por la "perpetuación del nexo fiduciario" ${ }^{25}$. En las elecciones de 2004, por el contrario, su salida del Gobierno era también clara (obtuvo 146 escaños frente a los 164 del Partido Socialista). O qué decir, retomando alguno de los supuestos apuntados antes, del Gobierno cántabro que permaneció en funciones durante nueve meses (desde noviembre de 1994 a julio de 1995) bajo la presidencia de una persona que había sido condenada a la pena de seis años y un día de prisión, siete de inhabilitación absoluta y siete de inhabilitación especial —comprendiendo la privación del cargo que ostentaba- ${ }^{26}$; comparemos esta permanencia en funciones con otra acontecida en esa misma Comunidad unos años después: así por celebración de elecciones en junio de 1999, donde el Partido que apoyaba al entonces Presidente incrementó en seis el número de diputados en el Parlamento. No parece preciso abundar en esta idea para mostrar la disparidad apuntada.

22 SATRÚSTEGUI, M., "El cese del Gobierno y el Gobierno cesante", cit., p. 366; SANTAOLALLA, F., "Artículo 101", cit., p. 1577.

23 Sobre esta cuestión, REVIRIEGO PICÓN, F., El Gobierno cesante o en funciones en el ordenamiento constitucional español, cit., pp. 221 a 233.

24 Recuérdese, por ejemplo, lo acontecido en la Comunidad de Madrid tras las elecciones de mayo de 2003, que terminaron dando lugar a uno de los más sorprendentes períodos de permanencia en funciones (véase, REVIRIEGO PICÓN, F., "Un supuesto de Gobierno en funciones. La ubicuidad de Ruíz-Gallardón Alcalde-Presidente" Revista Internauta de Práctica Jurídica, $n .{ }^{\circ} 13$, 2004).

25 REVENGA SÁNCHEZ, M., La formación del Gobierno en la Constitución Española de 1978 , cit., p. 68.

26 Véase, REVIRIEGO PICÓN, F., "La regulación del Gobierno en funciones en los ordenamientos autonómicos. A propósito del caso cántabro", El Gobierno, LUCAS MURILLO DE LA CUEVA, P. (Coord.), Tirant lo Blanch, Valencia, 2005, pp. 661 a 702. 
No obstante lo anterior, la importancia de esta diversa naturaleza, evidente a todas luces, se reconduce esencialmente al ámbito de lo político, en tanto que no cabe trasladar estos planteamientos al ámbito de la revisión jurisdiccional. La jurisdicción contencioso-administrativa debe limitarse, ante un eventual recurso frente a una actuación de un Gobierno cesante, a cotejar que la actuación de este Gobierno - más allá de las limitaciones específicas que por su claridad no precisan puntualización ahora - se ajusta a su finalidad y se encuadra en alguno de los tres conceptos bajo el que la Ley dibuja su competencia. La jurisdicción deberá valorar, así, si la decisión tomada puede considerarse o no un despacho ordinario de los asuntos públicos, y caso de no serlo, si dicha decisión ha obedecido al hecho de encontrarnos ante un supuesto de urgencia debidamente acreditado o una razón de interés general cuya acreditación específica así lo justifique; el hecho de que la prorrogatio de funciones fuere aquí formal o material, en la expresión de Revenga ${ }^{27}$, resultaría, o debiera resultar, indiferente.

Sobre todo ello volveremos al analizar las sentencias de 20 de septiembre y 2 de diciembre de 2005 del Tribunal Supremo. Pero antes parece preciso consignar unas reflexiones sobre el indulto y la extradición en nuestro ordenamiento jurídico, toda vez que las actuaciones controvertidas del Gobierno en funciones que estarán en el origen de las sentencias a comentar fueron precisamente una extradición, en uno de los casos, y un indulto, en el otro.

\section{EL INDULTO Y LA EXTRADICIÓN EN NUESTRO ORDENAMIENTO}

\section{III.1. El INDUlTo}

El derecho de gracia - anomalía, cuando menos teórica, en un Estado de Derecho $^{28}$, pero ardientemente defendido también, entre otros, por Hamilton para la República estadounidense ${ }^{29}$ - se encuentra regulado por una Ley que en sus casi ciento cuarenta años de existencia ${ }^{30}$ — más allá de su supresión durante unos meses en nuestra I República-, únicamente habría sido modificada en 1988, en orden a agilizar en alguna medida la tramitación de los expedientes de indulto, siendo afectada en todo caso también por la aprobación en 1995 del

27 La formación del Gobierno en la Constitución Española de 1978, cit., p. 68.

28 Así se refiere a esta institución M. ARAGÓN en el "Prólogo" al libro de AGUADO RENEDO, C., Problemas constitucionales del ejercicio de la potestad de gracia, Cívitas, Madrid, 2001, p. 17. J.F. LÓPEZ AGUILAR habla, por su parte, de una "pieza residual e incluso extraña en la economía del orden constitucional vigente", "Prólogo" al libro de GARCÍA MAHAMUT, R., El indulto. Un análisis jurídicoconstitucional, Marcial Pons, Madrid, 2004, p. 11.

29 HAMILTON, A., en El Federalista, HAMILTON, A., MADISON, A., JAY, J., FCE, 2001, artículo LXXIV (25-3-1788), pp. 317-318.

30 Una breve reseña histórica sobre esta prerrogativa en nuestra legislación puede verse en LINDE PANIAGUA, E., Amnistía e Indulto en España, Tucar, Madrid, 1976, esp. pp. 27 a 42. 
nuevo Código Penal ${ }^{31}$. Esta longeva Ley es en la actualidad objeto de un proyecto de reforma, habiéndose creado a estos efectos un grupo de trabajo dentro del Ministerio de Justicia ${ }^{32}$.

Nos encontramos ante un modelo gubernamental de indulto particular (como es sabido, la Constitución prohíbe la autorización de indultos generales) aunque en todo caso estaríamos ante uno de los más judicializados de nuestro entorno ${ }^{33}$.

Dicho cuerpo legal regula con detalle las clases y los efectos del indulto, las personas que pueden ser indultadas así como, por supuesto, el procedimiento para solicitar y conceder el mismo.

Conforme a esta regulación, podrán ser indultados los reos de toda clase de delitos de toda o parte de la pena en que por aquéllos hubiesen incurrido. Se establecen, no obstante, excepciones en sede legal y asimismo, no olvidemos, en el propio texto constitucional con relación a la responsabilidad criminal del Presidente y los demás miembros del Gobierno; esta sería una de las tres previsiones contempladas en nuestra norma suprema respecto de esta prerrogativa, junto con la atribución al Rey del ejercicio de ese derecho y a la prohibición de la iniciativa legislativa popular en esta materia ${ }^{34}$.

Por lo que aquí interesa es posible distinguir diversas cuestiones atinentes a este instituto.

Por un lado, el procedimiento en sí, que lógicamente puede ser en su caso controlado por la jurisdicción contencioso administrativa; la ausencia de algún elemento reglado podría determinar la anulación del Acuerdo del Gobierno. Como se ha reiterado en múltiples sentencias, el control que la jurisdicción contenciosoadministrativa puede ejercer sobre estos actos alcanza a "los aspectos formales de su elaboración, concretamente a si se han solicitado los informes que la Ley establece como preceptivos", aunque no vinculantes, "de aquí que entre dentro de la libertad estimativa del Consejo de Ministros el aceptar o discrepar de los mismos", hecho que ya entraría "dentro del ámbito de la política penitenciaria, materia que, por su misma naturaleza, escapa al control de la jurisdicción administrativa ${ }^{35}$.

31 Con relación a estas reformas, E. LINDE hace una valoración muy positiva de la última reforma, la de 1995, hablando, por el contrario, de una modificación "irrelevante" al referirse a la reforma de 1988; todo ello dentro de considerar que, en su conjunto, estamos ante una "regulación muy estimable y equilibrada cuya modificación resulta especialmente comprometida", "La clemencia (amnistía e indulto) a la luz de la jurisprudencia de los Tribunales Supremo y Constitucional y del Código Penal de 1995", Boletín de Información del Ministerio de Justicia, n. ${ }^{\circ}$ 1823, 1998, p. 13.

32 Sobre esta cuestión, véase la intervención del Secretario de Estado de Justicia L. LÓPEZ GUERRA ante la Comisión de Justicia, que tuvo su origen en una pregunta planteada respecto de la política de concesión de indultos llevada a cabo por el Consejo de Ministros, DSCD, n. ${ }^{\circ}$ 386, de 4 de octubre de 2005.

33 En este punto, LINDE PANIAGUA, E., "El indulto como acto de administración de justicia y su judicialización", Teoría y Realidad Constitucional, n. ${ }^{\circ}$ 5, 2000, pp. 161 y ss.

34 Un interesante estudio sobre la función constitucional del indulto y la acción del gobierno en nuestro Estado Social y Democrático de Derecho puede verse en GARCÍA MAHAMUT, R., El indulto. Un análisis jurídico constitucional, Marcial Pons, Madrid, 2004, pp. 207 a 254.

35 Ver, por todas, las SSTS de 16 y 21 de febrero y de 30 de septiembre de 2005 (Sala 3. ${ }^{a}$ ). 
Por otro, la concesión o denegación en sí; estaríamos aquí ante una facultad potestativa que no sería susceptible de recurso ante la jurisdicción contencioso administrativa. Se trata de un acto graciable en sentido estricto.

La eventual concesión, no olvidemos, estaría sujeta siempre a la previa aprobación judicial; y no habría que olvidar tampoco que la no resolución en un año del expediente de indulto determinaría la tácita desestimación del mismo.

La posible proyección política de este medio de extinción de la responsabilidad criminal resulta evidente en determinados supuestos ${ }^{36}$. Sin necesidad de apuntar un ejemplo tan espinoso - pero tan obvio- como el terrorismo, tenemos ejemplos mucho más pacíficos, como el que suscitara en su momento la objeción de conciencia al servicio militar obligatorio.

No obstante, tal proyección no existiría en la práctica totalidad de los supuestos, respondiendo más el ejercicio de esta prerrogativa a un intento de superar las "indeseables consecuencias a las que puede conducir una condena tardía, desproporcionada, extemporánea o individualizadamente injusta o antisocial, ${ }^{37}$ o respondiendo incluso a cuestiones de mera intendencia penitenciaria $^{38}$.

Volviendo la mirada atrás, resulta indudable que el supuesto más llamativo en esta materia lo constituyó aquel indulto, cuasi general, aprobado por el Consejo de Ministros en su reunión de 1 de diciembre de 2000.

En virtud de esta medida de gracia, ampliamente discutida, se llegó a indultar a mil cuatrocientos cuarenta y tres personas, indultos entre los que se contarían los de casi quinientos insumisos al servicio militar obligatorio, así como algunos otros especialmente polémicos por su evidente significación política.

36 JENNINGS, en su clásica obra sobre el Cabinet Government, ya apuntaba como no era imposible imaginar circunstancias en que el ejercicio del derecho de gracia sería de gran importancia política en tanto que "el perdón del autor de un crimen político, tal como un asesinato político, traición, rebelión, reunión ilegal, o libelo sedicioso, podría implicar cuestiones políticas de primer orden de magnitud. Ponía de ejemplo para ilustrar tal idea la propuesta de indulto de Sir R. Casement, condenado por traición por incitar a los soldados irlandeses a luchar en el lado alemán, que se llevó ante el Gabinete (en contra de la práctica de no llevarlo y dejarlo a la competencia del Home Secretary, por implicar "el ejercicio de una función judicial"). El propio Gobierno británico justifica la denegación del indulto, afirmó, entre otras cosas, que "the only ground for a reprieve would be political expediency, a difficult ground to put forward in this country. His country never could strain the law to punish a man for the same reason that it could not strain the law to let one off." (Source Records of the Great War, Vol. IV, ed. Ch. F. Horne, National Alumni, 1923).

37 J. F. LÓPEZ AGUILAR encuentra en estas razones la justificación al mantenimiento de esta institución, apuntando de forma ejemplificativa que "es el caso de quien estando resocializado desde hace años tenga que ingresar en prisión, o de quienes hayan cometido delitos próximos a desaparecer, o de quienes se hayan reinsertado y rehabilitado con carácter previo al ingreso en prisión, o de quienes hayan perdido cualquier asomo de peligrosidad, o de quienes hayan acreditado disposición y capacidad para volverse a reintegrar a la vida en libertad", Íbidem, p. 14.

38 Sobre esta cuestión, AGUADO RENEDO, C., Problemas constitucionales del ejercicio de la potestad de gracia, cit., p. 17. 
Esa cifra sería similar, mutatis mutandis, a los indultos que se aprobarían "como máximo" a lo largo de todo un año, pues como se vino en apuntar desde el Ministerio de Justicia al tiempo que éstos se concedían, tomando como referente la década de los noventa, el número de indultos concedidos oscilaría entre cuatrocientos cincuenta y mil quinientos.

En todo caso, lo cierto es que las cifras actuales serían muy inferiores, acentuando más, si cabe, lo sorprendente de aquella medida; así, por ejemplo, en 2004 y 2005 sólo se habrían concedido poco más de trescientos y cuatrocientos indultos, respectivamente ${ }^{39}$.

La discusión sobre la aprobación de esta medida no se limitó, en todo caso, al número exageradamente elevado de indultos concedidos, sino igualmente a la motivación esgrimida para su concesión, sobre la que huelga hacer comentarios ahora: el cambio de milenio, la petición de la Santa Sede por ser año jubilar, la celebración del vigesimosegundo aniversario del texto constitucional y los veinticinco años de la Monarquía ${ }^{40}$.

\section{III.2. LA EXTRADICIÓN Y ENTREGA}

La extradición, instrumento de cooperación en una sociedad interrelacionada y compleja fundamentada en un principio de solidaridad internacional ${ }^{41}$, es regulada en nuestro ordenamiento por la Ley 4/1985, de 21 de marzo que vino en sustituir a un cuerpo legal que databa de 1958 y que resultaba completamente inadecuado tras la ratificación de diferentes convenios europeos sobre la materia.

Dicha Ley regula detalladamente todas las cuestiones atinentes a la solicitud misma, extradición activa, como a la entrega, extradición pasiva.

Sin entrar ahora en detalle en el estudio de esta institución jurídica de antecedentes muy remotos ${ }^{42}$, y centrándonos en la segunda de las perspectivas, extradición pasiva, debemos apuntar que la decisión del Gobierno respecto de su concesión o denegación viene determinada, en un caso de forma vinculante y en otro no, por el criterio emitido por el Tribunal competente.

39 Los últimos datos ofrecidos desde el Ministerio de Justicia sobre esta figura apuntan que cada semana se elevan a Consejo de Ministros doscientos diez expedientes de conmutación total o parcial de las penas de los que sólo alrededor del 5\% obtienen resultado favorable. La actual política del Gobierno excluiría a priori de esta conmutación de pena a los condenados por delitos de violencia de género y maltrato familiar, racismo, delitos contra la seguridad en el tráfico y contra la libertad sexual, excluyéndose también esta medida en delitos graves que generen alarma social: tráfico de armas, asesinatos, torturas y genocidio.

40 Con relación a este indulto, GARCÍA MAHAMUT, R., El indulto. Un análisis jurídico constitucional, cit., esp. pp. 19 a 21 y 192 a 194; PÉREZ FRANCESCH, J.L., DOMÍNGUEZ GARCÍA, F., "El indulto como acto del Gobierno: Una perspectiva constitucional", Revista de Derecho Político, n. ${ }^{\circ} 53,2002$, esp. pp. 49 a 66.

41 MORENO CATENA, V., Derecho Procesal Penal, Colex, Valencia, 1999, p. 969.

42 Para un estudio de los antecedentes históricos de la extradición véase SEBASTIÁN MONTESINOS, M. A., La extradición pasiva, Comares, Granada, 1997, pp. 1 a 22. 
El criterio negativo a la extradición del Tribunal impide al Gobierno su concesión, mientras que, al mismo tiempo, el criterio positivo de aquél permite al Gobierno bien su concesión bien su denegación. Esta posibilidad quedaría abierta atendiendo a criterios de reciprocidad, soberanía, seguridad, orden público y demás intereses de nuestro país.

Esta última opción que se abre al Gobierno (inspirada en los sistemas francés e italiano y criticada por un sector de la doctrina que apuesta por un procedimiento exclusivamente jurisdiccional ${ }^{43}$ ) se vino en justificar en la exposición de motivos de dicho cuerpo legal sobre la base del "distinto campo y finalidad en que actúan y persiguen los Tribunales y el Gobierno; técnico y sobre todo tutelar del derecho a la libertad los primeros y políticos esencialmente el segundo".

Especial interés han revestido en los últimos años la concesión de extradiciones a condenados en rebeldía (recordemos el cambio de criterio de la Audiencia Nacional en esta materia a partir de 1997), dando lugar a numerosos pronunciamientos del Tribunal Constitucional sobre esta cuestión, sobre la base de la posible vulneración indirecta de derechos fundamentales al reconocer, homologar o dar validez a resoluciones que hubieren sido adoptadas por autoridades extranjeras.

Sería preciso hacer referencia aquí, como auténtico leading case, a la STC $91 / 2000$, de 30 de marzo $^{44}$, que determinaría la incompatibilidad con el "contenido absoluto" del derecho a un juicio justo (el que necesariamente ha de proyectarse ad extra, sea cual fuere el foro competente) de "la condena in absentia por un delito que lleve aparejada una pena grave sin ulterior posibilidad procesal de impugnación de la misma, a fin de subsanar el déficit de garantías que la falta de presencia del condenado en la vista haya podido ocasionar".

Esta idea llevaría a considerar contraria a las exigencias del artículo 24.2 del texto constitucional la concesión de "la extradición a países que, en casos de delito muy grave, den validez a las condenas en ausencia, sin someter la entrega a la condición de que el condenado pueda impugnarlas para salvaguardar sus derechos de defensa " ${ }^{45}$.

Hablar de este tema nos lleva indefectiblemente a hacer una breve reseña, en el ámbito de la Unión Europea, de los efectos de la adopción por el Consejo de Ministros de Justicia e Interior de la Unión Europea en junio de 2002 de la Decisión Marco relativa a la Orden de Detención Europea y a los Procedimientos de Entrega entre Estados Miembros, conocida coloquialmente como "euro-orden", parcialmente en crisis, como es bien sabido, tras la decisión de ju-

43 A título de ejemplo, GARCíA SÁNCHEZ, B., La extradición en el ordenamiento interno español, internacional y comunitario, Comares, Granada, 2005.

44 Más recientemente véase la STC 183/2004, de 2 de noviembre.

45 Un comentario de esta sentencia en REY MARTÍNEZ, F., "El problema constitucional de la extradición de condenados en contumacia. Comentario de la STC 91/2000 y concordantes", Teoría y Realidad Constitucional, n. ${ }^{\circ}$ 5, 2000, pp. 289 a 335. 
lio de 2005 del Tribunal Constitucional Federal Alemán que declaró inconstitucional la ley que desarrolló la decisión marco sobre la euro-orden por vulneración de derechos fundamentales ${ }^{46}$.

Sin querer entrar en un estudio en profundidad de la misma, apuntaremos únicamente que esta orden de detención europea es una "resolución judicial" dictada en el seno de un Estado miembro de la Unión con vistas a la "detención y entrega por otro Estado miembro de una persona buscada para el ejercicio de acciones penales o para la ejecución de una pena o una medida de seguridad privativas de libertad"; una entrega realizada sobre la base del "principio de reconocimiento mutuo" que no hace sino permitir la ejecución prácticamente inmediata de las resoluciones que fueren dictadas por las autoridades judiciales de los demás Estados.

Se trata de un procedimiento puramente judicial (algunos autores critican las previsiones normativas por un excesivo arbitrio judicial ${ }^{47}$ ), con mínima participación del Ejecutivo, y que agilizará sin duda todas estas cuestiones. No obstante lo anterior, la participación del Ejecutivo sí será determinante, por el contrario, en los supuestos de concurrencia de una "euro-orden" y una solicitud de extradición en tanto que en este último supuesto la autoridad judicial de ejecución española deberá suspender el procedimiento y remitir la documentación al Ministerio de Justicia, que elevará con posterioridad al Consejo de Ministros la decisión de dar preferencia bien a la "euroorden", bien a la solicitud de extradición.

Como se señaló en la Exposición de Motivos de la Ley 3/2003, de 14 de marzo, sobre la orden europea de detención y entrega, que pretende hacer efectivas en nuestro ordenamiento las obligaciones derivadas de aquella Decisión marco comunitaria, son tantas y tan sustanciales las modificaciones operadas en el clásico procedimiento de extradición que "puede afirmarse sin reservas que éste ha desaparecido de las relaciones de cooperación judicial entre los Estados miembros de la Unión European; el procedimiento de entrega a aplicar a partir de ahora, sustituyendo a aquél, permitirá que "esta forma de cooperación judicial directa opere de manera eficaz y rápida, entre Estados cuyos

46 Sentencia de 18 de julio de 2005, BVefG 18.07.2005 - 2 BvR 2236/04. Debemos apuntar igualmente que ha sido planteada por un tribunal belga una cuestión prejudicial ante el Tribunal de Justicia de las Comunidades sobre la Decisión Marco del Consejo de 13 de junio de 2002 relativa a la orden de detención europea y a los procedimientos de entrega entre Estados miembros.

Sobre la sentencia del Tribunal Constitucional Federal Alemán puede verse CUERDA RIAZU, A., "Comentario a la sentencia del Tribunal Constitucional Alemán de 18 de julio de 2005 que declara inconstitucional la ley alemana sobre la orden europea de detención y entrega", Revista Europea de Derechos Fundamentales, n. ${ }^{\circ}$ 6, 2005, pp. 149 y ss., y dentro de la doctrina alemana, el trabajo de TOMUSCHAT, C., "Ungereimtess: Zum Urteil des Bundesverfassungsgerichts vom 18. Juli 2005 über den Europäischen Haftbefehl", Europäische Grundrechte Zeitschrift, 2005, pp. 453 ss.

47 En este sentido, CUERDA RIAZU, A., De la extradición a la "euro-orden" de detención y entrega, Editorial Centro de Estudios Ramón Areces, Madrid, 2003. En sentido contrario, desde una perspectiva procesal, CALAZA LÓPEZ, S., El procedimiento europeo de detención y entrega, Iustel, Madrid, 2005. 
valores constitucionales se basan en el respeto de los derechos fundamentales y en los principios democráticos ${ }^{48}$.

\section{DOS RESOLUCIONES JUDICIALES CONTRADICTORIAS}

\section{IV.1. El GOBIERNO EN FUNCIONES DE MARZO DE 2004}

El traspaso de poderes del año 2004 ha sido indudablemente el más traumático de todos los que se habían verificado hasta la fecha, al quedar marcadas aquellas elecciones y la subsiguiente actuación del Gobierno, ya cesante, por el atentado terrorista más terrible sufrido en nuestro país.

Ello provocó, por ejemplo, que durante su propia permanencia en funciones (en todo caso, muy breve, la de menor duración si exceptuamos la que siguió a la dimisión del Presidente Suárez en $1981^{49}$ ) se tomaran determinadas decisiones que ya en esos momentos se planteó si escapaban al campo de acción de un gobierno en tal estado; recordemos, por ejemplo, la desclasificación de ciertos documentos del Centro Nacional de Inteligencia, previos al día de las elecciones generales del 14 de marzo (manejados desde el propio día de los atentados), que se encontraban directamente relacionados con éste y que se dieron a conocer tras la primera reunión del Consejo de Ministros después de la celebración de las elecciones generales.

En todo caso, más allá de este específico supuesto, no creemos equivocarnos si apuntamos que una de las cuestiones que más revuelo político suscitó, fue el posible nombramiento por parte de este Gobierno cesante (en puridad, propuesta) de dos magistrados del Tribunal Constitucional; la correspondiente cuota que por esas fechas correspondía renovar y que probablemente no se había realizado de manera previa a las elecciones por las previas expectativas de voto del partido en el Gobierno. Con buen criterio, finalmente, dicha decisión no fue tomada durante este período de permanencia en funciones.

Con ocasión de este específico tema se planteó un interesante debate público sobre la legitimidad o ilegitimidad de un Gobierno en este estado respecto de determinadas cuestiones, su competencia o incompetencia.

48 El último país que, hasta la fecha, ha declarado la aplicación de la orden de detención europea y los procedimientos de entrega en las relaciones con los Estados miembros ha sido Letonia (enero de 2006), véase la Resolución de 31 de marzo de 2006, de la Secretaría General Técnica, sobre la declaración de Letonia al Convenio Europeo de Extradición (número 24 del Consejo de Europa), hecho París 13 de diciembre de 1957 — BOE de 14 de abril de 2006-.

49 Treinta y cuatro días en 2004, frente a treinta en 1981; el período de mayor dilación de la permanencia en funciones de un órgano gubernamental se produjo por el contrario tras las elecciones generales de 1996 al mantenerse en funciones aquel gobierno durante dos meses (la razón ha de buscarse en el escenario político — desconocido hasta el momento- dibujado tras aquellas elecciones: el principal partido en la oposición había obtenido mejores resultados que el partido que apoyaba al Gobierno pero no alcanzaba la mayoría absoluta de los escaños parlamentarios). 
Evidentemente, la dialéctica política puso sobre la mesa otra serie de temas sobre los que unos y otros discrepaban a la hora de definir qué había de entenderse por ámbito de actuación normal, o quizá legítimo, de un gobierno en tal estado.

Especialmente llamativa sería también la decisión de la paralización temporal del relevo de las tropas desplazadas en Irak. No ya por el hecho en sí, que quizá hubiera podido cobijarse sin dificultad bajo esa idea de "abstención ante la duda" con que se configura en ocasiones la actuación de un gobierno en este estado, sino porque se sujetó dicho relevo al hecho de que quien probablemente habría de asumir la jefatura del gobierno manifestara de forma previa su asentimiento respecto de dicho relevo; de alguna forma, esa "excusa para la inacción" que vino en definir Bouyssou ${ }^{50}$, unida a una traslación de responsabilidad que se articulaba con dificultad con una decisión de ese tenor. Completamente diferente hubiera sido, por ejemplo, el envío de un mayor número de efectivos o el primer envío de los mismos.

En todo caso, como pudiera parecer previsible prima facie, o al menos así nos parece - aunque vayamos ya anticipando de alguna manera nuestro criterio sobre el contenido de las sentencias objeto de este comentario-, la concesión y denegación de indultos o de extradiciones pasaron completamente desapercibidas sin generar controversia alguna.

No había sido, evidentemente, la primera ocasión en que un Gobierno en este estado se había enfrentado a estas cuestiones. De hecho, haciendo recapitulación, se trata de decisiones habitualmente tomadas por Gobiernos cesantes y, más aún, en un plano exclusivamente numérico, ocupan parte importante de su gestión, lo que no impidió en todo caso que en sede doctrinal se haya planteado, ya con anterioridad al cambio de Gobierno de 2004, ciertas reticencias con relación a alguna de estas competencias (concesión o denegación de indultos) sobre la base, entre otros argumentos, de la discrecionalidad del gobierno en su decisión. Así, Guillén, en unas interesantes reflexiones sobre este punto, apuntaba que "la discrecionalidad, la imposibilidad de alcanzar las más altas consecuencias del control, y la irreparabilidad son argumentos más que suficientes para poner en cuarentena esta función durante el tiempo que el Gobierno esté en funciones"; a esta idea añadía que "los Gobiernos en funciones en España no han ralentizado esta función y que tampoco se les ha requerido, lo que puede dar una falsa idea de aproblematicidad que se advierte inmediatamente en cuanto se caiga en la cuenta de la trascendencia pública que pueden tener ciertos indultos $"$. Otro sector de la doctrina, por el contrario, y apoyado en esa misma experiencia práctica, apuntaba que el criterio del des-

$50 \mathrm{El}$ autor ejemplificaba esta idea apuntando determinadas decisiones/abstenciones (alguna ciertamente llamativa) tomadas por diferentes Gobiernos durante la IV República, “L'introuvable notion d'affaires courantes. L'activité des gouvernements demissionaires sous la Quatrième République", cit., pp. 655 y 663. Véase, también, MASCARENHAS GOMES MONTEIRO, A., "L'expedition des affaires courantes", Res Publica, 1978, pp. 440/441

51 El cese del Gobierno y el Gobierno en funciones en el ordenamiento constitucional español, cit., pág 104. 
pacho ordinario de los asuntos públicos debería interpretarse "con amplitud" y que los Gobiernos en este estado podrían "llevar a cabo válidamente una actividad administrativa relativamente extensa en la que pueden incluirse medidas de muy diverso tipo"; en ese sentido, Satrústegui que, haciendo una breve relación de algunas medidas tomadas por el Gobierno cesante el año 1996, apunta específicamente la aprobación de reales decretos de indulto ${ }^{52}$.

Cabe recordar que, a la vista de esta práctica de los diferentes Gobiernos cesantes, en el año 2000 (con ocasión de un traspaso de poderes meramente formal en tanto que el partido que sustentaba al Gobierno había obtenido mejores resultados que en los anteriores comicios, alcanzando incluso la mayoría absoluta), ambas competencias se entendieron incluidas de forma expresa como despacho ordinario de los asuntos públicos en la Nota Informativa de la Vicesecretaría General Técnica del Ministerio de Presidencia que se elevó al estudio del Consejo de Ministros, en su reunión de 17 de marzo de 2000, apenas unos días después de la celebración de las elecciones generales.

Concretamente, dentro de un extenso listado que ahora reproducimos parcialmente por su interés, se apuntó que «tanto por su carácter habitual o común, como por su proliferación durante períodos o etapas precedentes de diferentes 'Gobiernos en funciones' — sin que se hayan suscitado, en ningún caso, objeciones o reparos- pueden considerarse comprendidos en la noción de 'despacho ordinario de los asuntos públicos' las siguientes decisiones del Consejo de Ministros: Concesión o denegación de indultos; Ascensos del personal militar; Ceses de altos cargos; Concursos y situaciones dentro de la carrera fiscal; Concesión de condecoraciones; Resolución de recursos y reclamaciones; Autorizaciones para la celebración de contratos, salvo cuando se extiendan a varias anualidades; Tramitación de expedientes de extradiciones activas y pasivas; Autorizaciones para el traslado de personas condenadas; Declaraciones de urgente ocupación de bienes y derechos; Imposición de multas; Tomas de razón en relación con sentencias del Tribunal Supremo; Concesiones de la nacionalidad española; Habilitaciones y dispensas en materia de nacionalidad; Declaración de obras de emergencia; Convalidación de gastos; Autorizaciones a las Comunidades Autónomas para emitir deuda pública, concertar préstamos, emitir bonos u obligaciones, o realizar operaciones en divisas; Concesión de créditos con cargo al Fondo de Ayuda al Desarrollo; Reserva, a favor de la Administración General del Estado, de bienes de dominio público; Declaraciones de lesividad a los intereses del Estado en relación con la fijación de justiprecios; Reconocimiento de utilidad pública, a efectos de expropiación forzosa; Concesión de anticipos de tesorería; Cesión o uso gratuito de bienes propiedad del Estado; Acuerdos sobre declaraciones comunes de intenciones, firmas 'ad referéndum', tomas de conocimiento y canje de notas en el ámbito internacional».

52 "Artículo 101. El cese del Gobierno y el Gobierno cesante", cit., p. 363. 
Por lo que a la concesión de indultos se refiere, el Informe se apoyaba en los siguientes datos: los Gobiernos cesantes de 1993 y 1996 habían aprobado en total 538 reales decretos, de los cuales 227 corresponderían a indultos (si hacemos el cálculo, un 42,19\% del total); y en el caso de las extradiciones, de 920 acuerdos tomados, 112 habrían correspondido a extradiciones y traslados $(12,17 \%)$. El siguiente traspaso de poderes correspondiente a año 2000 ofrecería datos similares [de 137 reales decretos, 48 corresponderían a indultos $(35,03 \%)]$.

La concesión de indultos (no así los procedimientos de extradición) se ha abordado en ocasiones, aunque sin profundas reflexiones, en los tratamientos doctrinales sobre el ámbito de acción de los gobiernos durante los traspasos de poderes y ello por razones obvias (especialmente interesantes son las reflexiones de la doctrina italiana y alemana durante el primer tercio del siglo xx). Se señalaba, así, la imposibilidad de concesión de indultos que tuvieran clara significación política durante esos períodos mas admitiéndolos en el resto de supuestos.

La idea resultaba clara, pero evidentemente la concreción resultaría mucho más compleja, especialmente porque, incluso aunque existiera conformidad en la existencia de dicha significación política, habría elementos que podrían modular la posibilidad o necesidad de su adopción. Así, por ejemplo, la salud física o psíquica del candidato al indulto, siendo importante asimismo la valoración de otros elementos, como la iniciativa (particular, judicial, penitenciaria, gubernamental...), la tramitación del expediente, la valoración de los informes que en su caso se exigieren, etc.

La práctica comparada, por otro lado, nos muestra múltiples ejemplos de indultos polémicos durante estos períodos de transición. Dejando de lado el indulto del Presidente de los Estados Unidos Gerald Ford a su antecesor en el cargo, Richard Nixon, por el Watergate, que se suele considerar el indulto más famoso de todos los tiempos, o la amnistía del Presidente Carter a los desertores de la Guerra de Vietnam, quizá uno de los que más líneas desataron recientemente (en todo caso, la configuración teórica del período revestiría aquí ciertas singularidades en las que ahora no entraremos) aconteció con ocasión de aquel conflictivo traspaso de poderes que en enero de 2000 se produjo en los Estados Unidos, ya que apenas dos horas antes de abandonar la Casa Blanca el entonces Presidente, Bill Clinton, saltándose por otra parte todos los trámites tradicionales al respecto, aprobó 140 indultos y 36 conmutaciones de pena, y entre ellos el indulto del multimillonario Marc Rich — huido de la justicia desde 1983 por evasión de impuestos y comercio con Irán durante el secuestro de la embajada norteamericana por militares iraníes, y de quien se sospechaba que podría haber financiado las campañas políticas de su benefactor y su esposa, que fue objeto de investigación por parte de la Cámara de Representantes (Comité de Reforma del Gobierno), así como por el Senado (Comité de Asuntos Judiciales) y por la propia Fiscalía de Nueva York. Y es que en los Estados Unidos se habla, así, un tanto hiperbólicamente, de los indultos presidenciales de la "hora 24" o de "last minute pardon", entendiéndose que es lo que hace el 
Presidente (o algunos de ellos) en el último momento antes de abandonar la Casa Blanca (y ello impediría, en principio, cualquier impeachment que, en la plástica caracterización de Tocqueville, tendría por fin “arrebatar el poder, ${ }^{33}$ ), tradición que se remontaría ya a George Washington, quien concedió casi tantos indultos en su último día como Presidente como en los siete años juntos de su presidencia o al propio Lincoln, quien concedió en su último año el mayor número de indultos de toda su presidencia, y esto es en realidad una verdadera tendencia general, que se verificó en buena parte de las presidencias, ya sea en su último año (por ejemplo, Bush, Carter, Reagan o Ford), ya sea incluso en sus últimos meses o días (incluyendo aquí a Coolidge, Grant, Wilson, Hayes, Andrew Johnson, Franklin Roosevelt, Truman, Eisenhower, Ford, Carter, Reagan y Bush, quien concedió un indulto incluso a Cox - perteneciente a una familia benefactora de Bush y de su partido y condenado por fraude bancario-dos días antes de dejar la presidencia) ${ }^{54}$.

En el caso de las extradiciones, un examen de las tramitadas en Consejo de Ministros por el último Gobierno en funciones, el presidido por José María Aznar entre el 15 de marzo y el 14 de abril de 2004, permite constatar que dicho Gobierno en funciones, pese a su brevedad extrema, resolvió sobre cerca de un centenar de extradiciones (activas, pasivas, entregas) en los cuatro Consejos de Ministros celebrados (los de 17, 24 y 31 de marzo y 13 de abril).

Dicho esto, procede entrar ya en el estudio de las sentencias objeto de este comentario, con los mimbres que hasta este momento hemos venido articulando.

\section{IV.2. LA SENTENCIA DE 20 DE SEPTIEMBRE DE 2005 (Sección 6. a De la Sala Tercera)}

Esta sentencia tiene su origen en el recurso presentado frente al Acuerdo de Consejo de Ministros de 1 de abril de 2004 por el que se acordó la entrega de la recurrente a las autoridades italianas de conformidad con providencia dictada por la Sala de lo Penal de la Audiencia Nacional, de fecha 26 de abril de 2004. La recurrente entendía que dicho Acuerdo era una "decisión política internacional", por implicar "una deliberación sobre el fondo del asunto, en relación a cuestiones bilaterales con el país que reclama la extradición, ya que siendo la extradición un proceso incidental de un proceso sancionador, debe aplicarse el principio non bis in idem.

El Tribunal Supremo comienza por rechazar la tesis de la Abogacía del Estado de que sólo un Acuerdo denegatorio de la extradición (y no de concesión, como el que se impugna) excedería del límite impuesto al Gobierno en fun-

53 TOCQUEVILLE, A., La democracia, cit., p. 115.

54 Véase, RUCKMAN, P. S., "Last minute' pardon Scandals: Fact and Fiction", accesible en http://www.rvc.cc.il.us/faclink/pruckman/pardoncharts/Paper2.pdf, quien habla de una "gran tradición americana", en contra de lo sostenido por algunos. 
ciones por el art. 21 de la Ley del Gobierno. Recordemos que, de conformidad con las previsiones de la Ley de Extradición Pasiva, la decisión previa del Tribunal declarando procedente la extradición no es vinculante para el Gobierno (en este caso para el Gobierno que permanecía en funciones), que podría denegarla (cosa que no hizo aquí) atendiendo tanto a criterios de reciprocidad como a razones de seguridad, orden público o demás intereses esenciales para España; en cambio, si la resolución firme del Tribunal fuere denegatoria de la extradición, al Gobierno (en funciones o no) le estaría vedada en todo caso su concesión. Este rechazo procedería de que el Tribunal Supremo parte de la concepción de "la extradición pasiva como acto de soberanía del Gobierno en relación con otros Estados", concepción que parece encontrar sustento en la propia previsión de la Ley 4/1985 de que el Ejecutivo, una vez declarada procedente la extradición por el Tribunal (no, si se declara improcedente), puede denegar una extradición "en el ejercicio de la soberanía nacional". Y esta posibilidad del Ejecutivo de denegar la extradición declarada procedente por los Tribunales (desde una perspectiva penal y procesal técnica), a juicio del Tribunal Supremo, "exige al Gobierno hacer un juicio de valor para apreciar si concurren o no alguna de las circunstancias reseñadas para conceder o denegar la extradición pasiva a pesar de que la resolución del Tribunal penal la estimara procedente; en consecuencia, el Gobierno en funciones, al pronunciarse sobre la procedencia o no de la extradición pasiva ejercita siempre una facultad de valoración de los intereses nacionales que conlleva un juicio político que excede de la gestión ordinaria de los asuntos públicos, y priva al futuro Gobierno de una decisión política que en el ejercicio de su soberanía nacional le corresponde en orden a conceder o denegar la extradición pasiva".

Ello supone, según la sentencia que comentamos, que, al resolver sobre la extradición, el Gobierno en funciones se habría extralimitado en sus facultades y competencias, ya que el Tribunal Supremo interpreta la previsión del "despacho ordinario de los asuntos" recogida por el art. 21 de la Ley del Gobierno de la siguiente forma: "Gestión administrativa ordinaria ausente de valoraciones y decisiones en las que entren criterios políticos salvo que se motive debidamente la urgencia o las razones de interés general que justifiquen la adopción de medidas de otra naturaleza".

En esta afirmación se resume la concepción en que reposa la sentencia respecto de lo que ha de entenderse por "despacho ordinario" de los asuntos como competencia general ordinaria (a salvo de lo que exija una situación de urgencia o el interés general) del Gobierno en funciones. Y también, como se verá, aquí va a estar la completa discrepancia de fondo del Pleno, en su sentencia de 2 de diciembre de 2005, respecto de la doctrina sentada por la Sección 6. ${ }^{\mathrm{a}}$ en esta sentencia.

Desde nuestro punto de vista, la concepción de que partía esta sentencia de 20 de septiembre era una excesivamente restrictiva y limitadora de las previsiones legales en este punto, y de una interpretación excesivamente literalista en lo que se refiere a la naturaleza de la extradición. Es verdad que, en nuestro ordenamiento, el Gobierno en funciones puede denegar una extradi- 
ción informada positivamente por los tribunales "atendiendo al principio de reciprocidad o a razones de seguridad, orden público o demás intereses para España" y ello, además, según la propia dicción literal de la Ley de Extradición Pasiva, "en el ejercicio de la soberanía nacional.

A partir de esta regulación, en nuestro concepto, es aceptable considerar que los Acuerdos del Gobierno sobre extradición son "actos de soberanía", pero ello es algo compatible con la "gestión ordinaria" de los asuntos como actividad normal de un Gobierno en funciones, pues esa "gestión ordinaria" - dejando ahora de lado los casos de urgencia o en que esté en juego el interés general- no excluye el ejercicio de la soberanía nacional; dicho de otro modo, el ejercicio de la soberanía nacional no convierte, en sí mismo, a una actuación del Gobierno en funciones en una "gestión extraordinaria".

Aquí habrá que atender al caso concreto, pero, en todo caso, puede sentarse la regla general de que los Acuerdos del Consejo de Ministros no denegatorios de una extradición declarada procedente por los Tribunales, aun siendo ejercicio de la soberanía nacional, no serán "gestión extraordinaria" de los asuntos, y ello porque en tales casos, si bien hay formalmente un ejercicio de la soberanía nacional de tipo negativo (no se hace uso de la misma para denegar la extradición informada judicialmente de forma positiva), en la práctica simplemente se aprecia que no hay razones vinculadas a dicha soberanía que obsten a la concesión de la extradición, aunque desde luego, habrá que estar a cada caso particular para ver si ha habido o no una gestión extraordinaria. En caso de un Acuerdo del Consejo de Ministros denegatorio de una extradición declarada procedente por los Tribunales, hay, por el contrario, un ejercicio positivo de la soberanía nacional (se utiliza para denegar una extradición informada positivamente por los tribunales). Y además hay una separación del criterio del Tribunal (aunque el parámetro de decisión sea totalmente diverso, ya que, como dice la Exposición de Motivos de la Ley de Extradición pasiva, mientras los Tribunales actúan con una finalidad técnica, y sobre todo tutelar del derecho a la libertad, el Gobierno actúa en el campo político esencialmente), pero nada de ello hace que el Acuerdo haya de ser considerado en todo caso una "gestión extraordinaria". Habrá que estar a cada caso concreto, atendiendo a factores tales como la reciprocidad, los criterios seguidos hasta ese momento para extradiciones similares, la singularidad o no de la extradición en curso, la repercusión política de la decisión, su vinculación a los intereses de España en la esfera internacional, el resultado electoral previsiblemente continuista o no, etc.

Por todo ello, desde nuestro punto de vista, no es acertado considerar que un Acuerdo de extradición adoptado por un Gobierno en funciones es un acto de gestión extraordinaria. A nuestro entender, la regla general es la contraria, aunque podrá considerarse que no es una "gestión ordinaria" si las circunstancias del caso concreto permiten llegar a esa conclusión, si bien también es preciso consignar que la prudencia por parte de un Gobierno cesante, y la correlativa densidad de control de los Tribunales, han de ser mayores cuando se trata de Acuerdos denegatorios de una extradición que cuando se trata de 
Acuerdos de concesión (siempre previa declaración judicial de procedencia, pues sin esta el Gobierno no puede hacer otra cosa que denegar la extradición), ya que en el primer caso siempre se ejercita en positivo la soberanía nacional (y no es un mero ejercicio negativo de la misma) y hay una separación del criterio técnico del Tribunal, y estos son factores que, ya en abstracto, restan cierta ordinariedad, al menos, a la actuación gubernamental.

Por otro lado, en cuanto a la concepción general de entender que gestión "ordinaria" es la ausente de valoraciones y decisiones en las que entren criterios políticos, nos remitimos a lo que luego comentaremos al hilo de la sentencia de 2 de diciembre, sentencia que parte de una idea completamente opuesta en ese punto, aunque se hayan suavizado las formas de la disonancia, algo nada infrecuente. Pero permítasenos anticipar que nos parece aquí aplicable la opinión expresada, en la doctrina alemana de la época de Weimar, por Nawiasky en un trabajo sobre el Gobierno en funciones de Baviera, en donde apuntara que un Gobierno privado de todo carácter político no sería ya un Gobierno simplemente, sino una mera autoridad por ramos, que como tal no puede ser el órgano supremo del Poder Ejecutivo en el Estado ${ }^{55}$, que se supone que es lo que es un Gobierno, y que sigue siéndolo si está en funciones. Y tampoco puede desconocerse, como apunta Lutz, que la actividad de Gobierno en un Estado moderno no se puede agotar a largo plazo en planificar medidas particulares de hoy para mañana y hacerlas realidad, sino que exige cada día más una planificación y una adopción de acuerdos con bastante previsión y orientación al futuro, algo de lo que tampoco puede desentenderse un Gobierno en funciones si el Estado en su conjunto no quiere sufrir daños muy serios ${ }^{56}$.

\section{IV.3. LA SENTENCIA «OVERruling» DE 2 DE DiCiEMBre de 2005 (Pleno)}

Al igual que en la sentencia anterior, se plantea también aquí, aunque con resultado completamente diferente, si una determinada actuación (denegación de la concesión de un indulto en este caso) puede o no ser adoptada por un Gobierno en prorogatio. Más allá de que un buen orden de señalamientos hubiera debido permitir su resolución simultánea, la circunstancia de que la segunda sentencia haya sido dictada por el Pleno y no por una Sección, como la primera, permite aventurar que la segunda es, en realidad, un overruling más o menos disimulado, pero contundente, de la primera ${ }^{57}$.

55 NAWIASKY, "Geschäftsministerium in Bayern", Bayerische Verwaltungsblätter, 80, 1932, p. 35, cit. por LUTZ, R., Die Geschäftsregierung nach dem Grundgesetz, Duncker und Humblot, Berlín, 1969, p. 73, nota 32.

56 LUTZ, R., Die Geschäftsregierung nach dem Grundgesetz, cit., p. 73.

57 La sentencia de 2 de diciembre de 2005 trató de suavizar el abandono de la doctrina de la sentencia de 20 de septiembre, con esta "piadosa" afirmación: "Al resolver ahora de este modo, damos un nuevo paso en el proceso de definición, a partir de las previsiones constitucionales y legales, del estatuto del Gobierno en funciones. La Sentencia de 20 de septiembre de 2005 abrió el camino para 
Aunque no utilice literalmente la idea de los conceptos jurídicos indeterminados, al abordar la interpretación de la expresión "despacho ordinario de los asuntos públicos", salta a la vista que el Tribunal trata de emplear dicha técnica y habla incluso de que estamos ante un "concepto indeterminado necesitado de concreción". Es sabido que, según doctrina ya tradicional, los conceptos jurídicos indeterminados son una técnica que facilita la aplicación de ciertos conceptos jurídicos de gran vaguedad, ambigüedad (deliberada o no: pueden ser "Compromisos apócrifos" en el sentido de Schmitt, pero no tienen por qué serlo) o imprecisión inicial, distinguiendo en su estructura «un núcleo fijo o 'zona de certeza' positiva, configurada por datos previos y seguros; una zona intermedia o de incertidumbre, o 'halo del concepto', más o menos imprecisa; y, finalmente, una 'zona de certeza negativa', también segura en cuanto a la exclusión del concepto" ${ }^{58}$. Los conceptos jurídicos indeterminados no hacen referencia, sin embargo, a la discrecionalidad administrativa, pues mientras cuando se trata de esta, como dice la STS de 1 de julio de 1991, "la Administración tiene una libertad electiva entre las distintas alternativas que se le presentan, pues, todas ellas son igualmente justas", el concepto jurídico indeterminado, sin embargo, "supone un proceso reglado, en el que el Tribunal habrá de valorar si, tratándose de la interpretación de la norma que ha creado el concepto, la Administración ha adoptado no cualquiera, sino la única de las soluciones justas que la interpretación permite y que no dependen de la voluntad

precisarlo, afrontando cuestiones antes no resueltas por la jurisprudencia, pues las ha planteado una Ley reciente que utiliza conceptos necesitados de interpretación. Precisamente, por eso, podemos ahora, tras un examen detenido de los problemas y argumentos puestos de manifiesto entonces, así como de los que ahora se han suscitado y de las normas y los principios constitucionales aplicables, avanzar en esa tarea para llegar a las conclusiones que se han explicado". Pero se ajusta mucho más a la realidad la valoración del Magistrado Sr. Garzón: "Respecto a la hipotética contradicción entre esta sentencia y la dictada por la Sección Sexta el 20 de Septiembre de 2005, no ofrece dudas, para mí, tal contradicción. La afirmación que se hace en la sentencia de la que discrepo en el sentido de que lo que le está vedado al 'Gobierno en funciones', es la decisión de asuntos que impliquen 'nuevas orientaciones políticas' no me parece conciliable con la contenida en la sentencia de 20 de Septiembre de 2005, en la que se afirma que el despacho ordinario es la 'gestión administrativa ordinaria ausente de valoraciones y decisiones en las que entren criterios políticos salvo que se motive debidamente la urgencia o las razones de interés general que justifiquen la adopción de medidas de otra naturaleza'. Ciertamente, esta modificación de criterios, en sentencias tan cercanas en el tiempo, y de modo consciente, es preocupante, pero no es infrecuente". La afirmación de la mayoría parece obedecer, en última instancia, a un intento de hacer lo más pacífica posible la sentencia, pero no puede esconder lo que realmente supone dicha resolución: una interpretación completamente diversa de lo que ha de entenderse por despacho ordinario de los asuntos públicos. A estos efectos, resulta ciertamente significativo que dos de los cinco votos particulares emitidos a esta segunda sentencia vengan avalados por la práctica totalidad de los magistrados que integraron la sección que dictó en su momento la primera de las sentencias; y en todo caso, su lectura pone de relieve la flagrante contradicción entre la doctrina que una y otra sentencia sientan. Estamos, pues, ante un verdadero "overruling", aunque haya que esperar a que se dicte, al menos, otra sentencia análoga para que podamos hablar de overruling jurisprudencial en un sentido técnico, que requiere reiteración de doctrina.

58 GARCÍA DE ENTERRÍA, E., FERNÁNDEZ., T. R., Curso de Derecho Administrativo, Civitas, Madrid, 1986, p. 436. 
del que interpreta, como concurriría si de un acto discrecional se tratara". No obstante, los conceptos jurídicos indeterminados pueden conllevar la existencia y reconocimiento, no de facultades discrecionales en ningún caso, pero sí de una libertad de apreciación, como reconoce la STS de 12 de diciembre de 2000 (nombramiento de los "candidatos más adecuados" como Fiscales del Tribunal Supremo), libertad de apreciación que, en todo caso, "no se traduce en una libertad omnímoda ni en una ausencia o imposibilidad de control jurisdiccional, sino simplemente en esto: rige la constitucional interdicción de la arbitrariedad; pero incumbe probar, a quien sostenga que fue incumplida, los hechos que permitan apreciar que se obró con evidente error o clara irracionalidad". Esta libertad de apreciación, sigue diciendo dicha Sentencia, «aparece referida al margen de apreciación que necesariamente conlleva la individualización de la única actuación legalmente autorizada para atender aquel interés, y que sólo genéricamente ha sido definida. Y para ese margen de apreciación suele aceptarse la amplia extensión que existe hasta el límite que representa la irracionalidad o la ostensible equivocación (..) Ello es lo que explica que en la mayoría de sus manifestaciones no esté establecida la exigencia formal de la motivación. El control ha de ser realizado, pero no desde la averiguación de cuál pudo haber sido el interés público legitimador de la actuación administrativa, sino desde el diferente parámetro de la racionalidad de esta última".

Pues bien, creemos que el Tribunal Supremo aplica grosso modo, aun sin declararlo explícitamente, esta técnica en la interpretación de lo que ha de entenderse por "despacho ordinario" de los asuntos públicos en el caso que analizamos:

a) En primer lugar, no se plantea qué ha de entenderse por "asuntos públicos", pues no era controvertido en el caso que la resolución de una petición de indulto es un "asunto público".

b) En cuanto a lo que sea, o no sea, el "despacho ordinario" de tales asuntos, delimita el Tribunal Supremo el concepto desde una triple dimensión, conforme a la técnica de los conceptos jurídicos indeterminados:

i. Por un lado, desde una perspectiva positiva, afirma el Tribunal que «el despacho ordinario de los asuntos públicos comprende todos aquellos cuya resolución no implique el establecimiento de nuevas orientaciones políticas ni signifique condicionamiento, compromiso o impedimento para las que deba fijar el nuevo Gobierno". Y esa cualidad que excluye a un asunto del despacho ordinario ha de apreciarse, caso por caso, atendiendo a su naturaleza, a las consecuencias de la decisión a adoptar y al concreto contexto en que deba producirse" (zona de certeza positiva). Así pues, "despacho ordinario" es toda actuación gubernamental que no establezca orientaciones políticas nuevas ni tampoco implique un condicionamiento, compromiso o impedimento para las actuaciones que pueda querer desarrollar el nuevo Gobierno llamado a sustituir al que ahora sólo está en funciones, algo que hay que determinar "caso por caso". 
Frente a este concepto relativamente amplio de "despacho ordinario" de los asuntos públicos formula su voto particular el Magistrado Sr. Bandrés, para quien dicha expresión o concepto ha de interpretarse con criterio no expansivo, sino restrictivo (también lo defienden así, "en el caso de dudas", el Magistrado Sr. Sieira y otros en su voto particular). Este Magistrado, Sr. Bandrés, comparte la idea de la mayoría de que la restricción de la actividad del Gobierno en funciones al "despacho ordinario" de los asuntos públicos priva a este de la capacidad de "dirección de la política interior y exterior", pero estima "que esta declaración jurídica debe completarse significativamente, porque el círculo que delimita el ámbito de actuación del Gobierno en funciones debe trazarse con arreglo al 'telos' del precepto enjuiciado, atendiendo, esencialmente, a la posición institucional de prorrogatio del gobierno cesante, que sirve de fundamento a la restricción de sus atribuciones y funciones, y que por ello debe acoger, además, otros contenidos reduccionistas derivados de la necesidad de asegurar, exclusivamente, la continuidad de la administración ordinaria de los asuntos públicos del Estado", todo ello basado en la idea fundamental de que "un Gobierno en funciones, que tiene limitados sus poderes y difuminada su responsabilidad parlamentaria, no puede acordar decisiones de trascendencia política al deber limitarse, en el ejercicio de sus funciones constitucionales, a asegurar, estrictamente, el regular funcionamiento de los asuntos y servicios públicos". Y en concreto, la resolución de un indulto, con independencia de si es denegatorio o no, sería para él: a) por naturaleza y en abstracto, una decisión inscribible en la categoría de actos de especial relevancia y trascendencia política»; b) una decisión de "significado esencialmente político" y "carácter excepcional" (conforme a nuestra tradición jurídico-constitucional); y c) en fin, un acto que afecta al principio de división de poderes y supone un desarrollo de una política criminal y de seguridad pública. Todo lo anterior es lo que le permitiría concluir que estamos ante un terreno vedado a un Gobierno cesante, salvo en caso de urgencia o cuando lo exija el interés general o público. Es claro, pues, que dicho Magistrado no sólo alcanza un resultado contrario al de la mayoría, sino que además ello se sustenta en una interpretación del "despacho ordinario" que restringe notablemente la que la mayoría propugna en la sentencia.

Por su parte, el Magistrado Sr. Garzón defiende un concepto del "despacho ordinario" que lo restringe a "los actos típicos (u ordinario) de la función administrativa tales como: autorizar, sancionar, contratar, expropiar, etc", y cree que el Gobierno en funciones no sólo no puede establecer «nuevas orientaciones políticas" ni condicionar al nuevo Gobierno, sino que tampoco siquiera puede llevar a cabo "las viejas políticas" del Gobierno cesado. Y considera que el indulto no es función administrativa, por lo pronto ya desde una perspectiva formal, pero tampoco desde una perspectiva materialontológica: «Es una prerrogativa de hondo calado político y constitucional, esencia que no se pierde por el uso inmoderado y trivialización de esta potestad por parte de los Gobiernos". Por ello, el Gobierno en funciones carece de competencia para resolver sobre un indulto, sea para concederlo o sea para denegarlo. 
También el voto particular firmado por los Magistrados Sres. Sieira, Lecumberri, y Robles (esta última inicialmente designada como ponente de la sentencia), al que se adhieren los Magistrados Sres. Peces y Frías, sigue un criterio más restrictivo. Estos Magistrados "se sitúan en la línea de quienes después de precisar que un Gobierno en funciones no puede tomar las decisiones políticas o de impulso que tomaría de no haber cesado, razonan que su margen de actuación se conformaría por una serie de atribuciones que podrían encuadrarse dentro del concepto de administración o de 'continuidad de la actividad pública necesaria' y siempre con el objetivo último de la consecución, en línea con lo recogido en la Exposición de Motivos de la Ley, de un normal desarrollo del traspaso de poderes al nuevo Gobierno y más cuando el nuevo Ejecutivo va a ser de signo político diferente". Este voto particular insiste en que el acuerdo sobre el indulto es una facultad regia, "residuo del poder absoluto del Soberano"; un acto siempre de "carácter extraordinario" (y sólo por ello no puede ser gestión "ordinaria", por frecuente que sea), y una "quiebra" del principio de separación de poderes; que tanto la concesión como la denegación "puede generar efectos irreparables", así como subraya que "el evidente ( ic ) contenido y relevancia política de la valoración para conceder o denegar un indulto" en ciertos casos en la historia reciente de nuestro país (su concesión y también su denegación "pueden ser utilizadas como instrumento de dirección política con consecuencias importantes tanto en el ámbito nacional, como incluso con proyección internacional") "deviene patente y manifiesto", y "hace imposible entender que se trataba de actos de gestión ordinaria ya que además de la motivación política que los presidía, constituyen la clara manifestación de una concreta dirección política en cuestiones referidas a temas tan esenciales como lo son la seguridad del Estado o la defensa nacional".

ii. Por otro lado, desde una perspectiva negativa, el Tribunal aprecia que «ese despacho no es el que no comporta valoraciones políticas o no implica ejercicio de la discrecionalidad. Tampoco el que versa sobre decisiones no legislativas" (zona de certeza negativa). Y es que una concepción distinta, como la sustentada por los recurrentes (pero también, en el fondo, aunque el Tribunal no lo diga, por el propio Tribunal, en concreto por su Sección 6. ${ }^{\mathrm{a}}$, en su sentencia de 20 de septiembre de 2005), "supondría situar al Gobierno en una posición de precariedad tal que podría impedir o dificultar que ejerciera los cometidos que la Constitución le ordena realizar, pues en pocos actos gubernamentales están ausentes las motivaciones políticas o un margen de apreciación". Tampoco parece suscribible la idea defendida por el Magistrado Sr. Puente Prieto en su voto particular a la sentencia que ahora comentamos, proponiendo seguir la clásica distinción entre los "actos políticos" (concebidos así "por la materia" sobre la que versan: en concreto, según el Consejo de Estado francés, "las relaciones internacionales, las relaciones interconstitucionales del Ejecutivo con los demás poderes y las cuestiones de gracia y amnistía", también la extradición), que estarían vedados al Gobierno en funciones, y los actos administrativos, con relación a los cuales habrá que analizar "caso por caso" si exceden o no del objetivo de la consecución de un normal desarrollo del pro- 
ceso de formación del nuevo Gobierno, y del "despacho ordinario", y si condicionan o no la legítima actuación administrativa del nuevo Gobierno. En concreto, para este Magistrado, el indulto, en todo caso, sería un acto político, y no un "auténtico acto administrativo", por ser un privilegio o prerrogativa de la Corona y de "naturaleza jurídica excepcional" (sic), como su propia historia revelaría, y por ello el Gobierno en funciones no podría resolver sobre el mismo (salvo que hubiera razones de urgencia, como el transcurso del plazo de desestimación por silencio) y menos todavía sobre un número considerable o inusual de indultos, lo que podría condicionar la política criminal del nuevo Gobierno, argumentación con la que coincide sustancialmente también el Magistrado Sr. Garzón. Desde nuestro punto de vista, el hecho de que formal e históricamente el indulto sea una prerrogativa regia es algo que no ha de tener mayor relevancia desde el momento en que materialmente, y así lo dice la Sentencia con atino, es siempre el Gobierno quien resuelve realmente sobre la concesión o denegación, a lo que podríamos añadir que, dentro de la lógica constitucional, la atribución formal al Monarca del derecho de gracia, como vía por la que puede llegar a dejarse excepcionalmente sin efecto una sentencia penal condenatoria en cuanto a la pena, es el correlativo de la circunstancia de que tal sentencia siempre se habrá dictado, formalmente, "en nombre del Rey", como toda la administración de justicia por jueces y tribunales, y tan formal es esa atribución regia del indulto como el mandato de que la justicia se administre "en nombre del Rey" (el Monarca es un puro centro de imputación formal tanto de la sentencia penal condenatoria respecto de la que se solicita el indulto como de la resolución sobre el indulto).

En unas coordenadas similares se sitúa el voto particular suscrito conjuntamente por varios magistrados, en el que se sostiene que "por despacho ordinario habrá de entenderse el conjunto de actos encaminados a la consecución de fines objetivos, generales y permanentes, quedando, por tanto, excluidos los actos políticos que incidan en la línea política del Gobierno y los actos administrativos que puedan tener por su contenido incidencia similar. Se encuadran también en la idea de despacho ordinario las decisiones de pura gestión administrativa, es decir, aquellas que responden a la actividad cotidiana de la Administración y que por tanto están ausentes de análisis o valoración por el Consejo de Ministros que se limita a aprobarlas, así como las decisiones que son consecuencia de otra anterior e improrrogable, para una eficaz gestión del servicio publico, es decir funciones de ejecución y administración (..). Es cierto, sin embargo, que no cabe identificar la idea de despacho ordinario con la mera administración o ejecución, y por tanto con la de actos administrativos. La multiplicidad de situaciones y contextos que se pueden presentar imposibilita esta identificación, piénsese en la decisión de ejecución de las obras públicas incluidas en un Plan General aprobado por una decisión política del Gobierno anterior no compartida por el partido que ha ganado las elecciones y que se aparta abiertamente del programa político de éste (..) Lo anterior nos lleva a disentir de la afirmación que se contiene en la sentencia de instancia en el sentido de que sólo lo que supone dirección política con mayúsculas esta ve- 
dado a un Gobierno en funciones y que por tanto no lo están los actos políticos en sentido estricto y los administrativos no susceptibles de ser calificados como de despacho ordinario en cuanto comportan contenido o valor político fruto de una valoración de esa naturaleza, salvo claro está razones de urgencia o interés general debidamente acreditadas. No cabe aceptar que corresponda a un Gobierno en funciones aquellas de carácter administrativo que condicionen, limiten o impidan el ejercicio de las mismas al nuevo Gobierno en función de sus propias valoraciones de carácter político, salvo en los mismos supuestos antes excepcionados".

iii. En cuanto, en fin, al "halo" del concepto jurídico indeterminado "despacho ordinario", insiste el Tribunal en "la necesidad de examinar caso por caso y asunto por asunto los actos que han de considerarse incluidos en el despacho ordinario y los que, por quedar fuera de él, no pueden ser abordados por el Gobierno en funciones de no existir urgencia o demandarlo el interés general"; por ello, cuando surja controversia al respecto, habrá que analizar casuísticamente si el acto discutido es o no un acto que puede considerarse de "dirección política" o un condicionamiento, compromiso o impedimento para las actuaciones del futuro Gobierno, para lo que habrá de atenderse a "la decisión de que se trate", a "sus consecuencias" y a "las circunstancias en que se deba tomar" (zona de penumbra o incertidumbre). A la vista de ello, es claro que, si aceptamos la distinción entre conceptos jurídicos indeterminados de experiencia y de valor, en el caso del "despacho ordinario" de asuntos públicos nos encontramos ante un concepto jurídico del segundo tipo, fundamentalmente. Y respecto del halo o zona de incertidumbre de los conceptos jurídicos indeterminados (de tipo valorativo, en concreto), dice la jurisprudencia (STS de 19 de julio de 2000) «sin hacer, por supuesto, aplicación de la presunción «iuris tantum" de validez de los actos administrativos, ni rescatar siquiera la doctrina que otorgaba a la Administración el "beneficio de la duda" en los casos complejos en los que la zona oscura del concepto requiere un mayor contacto con los hechos y un conocimiento técnico preciso- sí resulta necesario, para rectificar la apreciación que de aquél haga la Administración, acreditar que ésta ha obrado con arbitrariedad o irrazonabilidad, si se trata de conceptos que implican la utilización de criterios valorativos (cfr. STS 25 mayo 1998)".

La principal crítica de algunos votos particulares a la sentencia va dirigida precisamente contra el carácter esencialmente casuístico de la interpretación sentada por la mayoría. Así, Espín subraya que la interpretación de la mayoría "Conduce a este Tribunal a una difícil posición en el futuro, cual es la necesidad de dilucidar en cada ocasión en que se impugne la legalidad de una decisión de un Gobierno cesante si dicho acto supone o no - al margen, claro está, de los requisitos procedimentales y reglados que puedan existir- poner en juego la dirección política del Estado o, en otros términos, si constituye un acto de dirección de la política interior o exterior del Estado en la dicción del artículo 97 de la Constitución. Y tal criterio no puede formularse en términos de estricta legalidad, puesto que actos de una misma categoría (indultos, extradiciones) pueden constituir en unas ocasiones actos de dirección política del Estado por 
su significado concreto - por ejemplo, el indulto de una personalidad destacada en función de una decisión política de dar por zanjados hechos del pasado-, y en otras ser más bien actos de gestión o de puro trámite. Y el criterio decisivo, el significado que cada acto en concreto tenga para la dirección política del Estado y para la política y el programa del Gobierno, no es sino un juicio político stricto sensu cuya emisión pertenece plenamente al Gobierno o a las fuerzas políticas y parlamentarias, pero en modo alguno a este Tribunal Supremo".

Desde nuestro punto de vista, si bien es cierto que la interpretación del Tribunal Supremo del "despacho ordinario de los asuntos públicos" en cuanto "Contenido natural" del Gobierno en funciones como un concepto jurídico indeterminado de tipo valorativo conlleva estimaciones y ponderaciones muy apegadas al caso concreto, y con una atención detallada al supuesto de hecho de que se trate ${ }^{59}$, ello no implica en absoluto una mutación de un juicio jurídico en otro "político stricto sensw" por el hecho de que haya que valorar "el significado que cada acto en concreto tenga para la dirección política del Estado y para la política y el programa del Gobierno". Por otro lado, el carácter casuístico resulta relativizado por el hecho de que la valoración realizada por el Tribunal Supremo permitirá ir sentando una red de precedentes que será cada vez más tupida, y ello posibilitará sentar reglas generales.

Por ejemplo, simplemente la sentencia que comentamos nos permite sentar la pauta de que «un indulto denegado por un Gobierno en funciones no es un acto de dirección política del Estado, salvo que concurran circunstancias singulares". Aunque la sentencia analizada, muy apegada al caso particular sub judice, no lo aclara (ni tenía que hacerlo), parece traslucirse que, si el acuerdo sobre el indulto no es denegatorio es probable que tampoco haya de ser considerado, como regla general, un "acto de dirección política del Estado", si bien en tal caso, al no dejar el acuerdo sobre el indulto "inalterados" los términos de la sentencia judicial firme correspondiente ni impedir la concesión del indulto por un nuevo Gobierno, las probabilidades de que sea así en un caso más o menos singular se incrementan ${ }^{60}$. Pero si el indulto, especialmente si no

59 Como dice la STS de 9 de julio de 2001 con relación a los conceptos jurídicos indeterminados, "no debe olvidarse que estamos ante un supuesto de interpretación aplicativa y no meramente teórica de la norma, en la que la conexión entre ésta y el presupuesto de hecho determinante de su aplicación, no sólo es necesario, sino también deseable; que no se trata de hacer construcciones jurídicas de tipo abstracto con validez atemporal, sino de descender del plano de la categoría al de la anécdota (y viceversa también, en la fase consecuente de comprobación de que el caso encaja en la medida que aquélla —es decir, la norma- es)".

60 No le falta razón al Magistrado Sr. Garzón cuando reprocha a la mayoría que «la cuestión a decidir es si el "Gobierno en funciones" es competente o no para decidir la solicitud de indulto con independencia de su contenido, pues parece evidente que no puede afirmarse que es competente para su denegación y no lo es para la concesión". En la misma línea, el voto particular suscrito por el Magistrado Sr. Sieira Míguez y otros, apunta que «tampoco es asumible por quienes firmamos este voto particular hacer depender la idea de gestión ordinaria de la concesión o denegación del indulto por entender que esta última no es irreversible. En primer lugar el carácter de ordinario va vinculado a la función, por mucho que circunstancias concurrentes puedan incidir, 
es denegatorio, afecta a un relevante político (por ejemplo, un ex ministro condenado por terrorismo de Estado), o a una relevante personalidad (por ejemplo, un juez de la Audiencia Nacional condenado por prevaricación), o concurren otras circunstancias singulares (imaginemos por ejemplo indultos concedidos a miembros de la organización terrorista ETA por causa de la existencia de un proceso de negociación como el ahora abierto), la regla general de que el indulto no es un acto de dirección política puede invertirse, y habrá que atender al caso particular. Si tales singularidades no se dan, la jurisprudencia sentada sólo en esta primera sentencia permite ya de entrada considerar que el Gobierno cesante tenía competencia para resolver sobre el indulto, especialmente si este ha sido denegatorio. Por supuesto, a medida que la jurisprudencia sobre este tema (y los acuerdos de indulto son los más frecuentemente adoptados por un Gobierno en funciones) vaya siendo más abundante, los criterios que nos proporcionará serán más seguros, firmes y nos facilitarán afinar el juicio, y también incrementarán la seguridad jurídica, para el Gobierno y para los ciudadanos.

Una jurisprudencia similar podría irse fijando en materia de extradición y entrega europea, subvenciones, etc, de modo tal que no desaparecerá la importancia de la contemplación del caso concreto sub judice, pero se irá tejiendo una red cada vez más tupida que nos permita fijar con precisión cada vez mayor los linderos del concepto jurídico indeterminado "despacho ordinario" de los asuntos públicos.

Todo ello, hay que subrayarlo, no es nada nuevo para la jurisdicción contencioso-administrativa, sino un elemento bien característico de la misma, y bien conocido también por cuantos se hallen familiarizados con el Derecho administrativo contemporáneo, por más que el casuismo a que conduce, desde luego bastante relativizado por las razones anteriormente expuestas, haya sido criticado por algunos y ciertamente, pensamos que la propia mayoría del Tribunal Supremo ha contribuido a un cierto alarmismo disidente en su seno sobre este punto al recalcar tanto la necesidad de una ponderación casuística ("caso por caso y asunto por asunto") y no apuntar a la relatividad de la misma en función de lo que venimos aquí sosteniendo.

También el voto particular firmado por el Magistrado Sr. Sieira y otros parece rechazar una manifestación más concreta del casuismo sobre el indulto en concreto: «No es admisible otorgar o negar competencias a un Gobierno en funciones

tales como cual sea la causa de la situación "en funciones" u otras, pero siempre esa incidencia lo será sobre la función en sí y no sobre el contenido de la decisión que se tome, puesto que la denegación implica la valoración de la procedencia de la concesión y es esa valoración la que conlleva la carga que la diferencia de la gestión ordinaria. Por otra parte es también cuestionable la idea de reversibilidad de la denegación ya que al menos en cuanto al mayor tiempo que debe permanecer en prisión el peticionario del indulto la situación es irreversible, siendo evidente que en el caso que nos ocupa, en el que se había acordado la suspensión de la pena de tres años de privación de libertad, la denegación del indulto comporta el ingreso automático del actor en prisión, y atendida la duración de la pena impuesta y la propia tramitación del expediente de indulto, aún cuando aquel pudiera reproducir su solicitud de indulto ante el nuevo Gobierno salido de las urnas, el resultado final podría hacer ilusoria la petición formulada, al haber extinguido ya la pena privativa de libertad". 
para valorar la conveniencia o inconveniencia de un indulto y pronunciarse finalmente sobre él, según que el solicitante del derecho de gracia fuera alguien con cualquier género de proyección pública o social o careciera de ella, o en función de la naturaleza o relevancia social del propio delito cometido". Este planteamiento no nos parece suscribible, pues no cabe duda que tales factores, junto a otros muchos eventualmente, son relevantes, no por sí mismos, sino en cuanto que pueden conllevar una transformación o mutación de un indulto "de despacho ordinario" en otro que, por marcar una orientación política novedosa con implicaciones de ese tipo de largo alcance, no pueda considerarse ya como un "despacho ordinario".

Sea como sea, esta importante construcción jurisprudencial general-abstracta del Tribunal Supremo sobre el "despacho ordinario" de los asuntos públicos, modestamente disimulada en unas simples consideraciones de conjunto, desemboca, fiel a sus propias premisas, en un análisis abstracto-concreto fuertemente ligado al particular caso sub judice:

a) En primer lugar, comienza el Tribunal, en un enfoque abstracto y atendiendo a la regulación constitucional y legal, por sindagar sobre el significado del indulto desde la perspectiva de la dirección política de la que venimos hablando". Así, de un lado, aprecia que la facultad de indulto, aunque formalmente es una atribución del Rey, materialmente es una función gubernamental; de otro, subraya que se prohíben expresamente los indultos generales, lo que implica que "su significación, en principio, tiene un carácter particular y concreto". Además, recalca que de la regulación de la Ley de Indulto se desprende, al tratarse siempre de indultos particulares (como exige la Constitución), "la importancia que han de tener (...) los hechos y circunstancias del caso concreto, sobre los que debe extenderse la motivación que ha de contener el Real Decreto en que se manifieste", motivación que deberá contemplar de manera especial «las consecuencias que haya de producir bajo el aspecto de la justicia, de la equidad y de la conveniencia social, pues son extremos cuyo estudio impone la Ley. Por tanto, el indulto comporta una decisión circunscrita a un supuesto específico: el del reo al que se refiere, ya lo haya solicitado él o sean otros quienes lo hayan pedido en su nombre, entre los que puede estar el mismo Tribunal sentenciador, tal como lo prevén el artículo 20 de esta Ley y el artículo 4.3 del Código Penaln. Las consideraciones abstractas anteriores permiten al Tribunal Supremo alcanzar una conclusión general o abstracta respecto de la competencia del Gobierno en funciones para resolver sobre un indulto planteado: «El acuerdo del Consejo de Ministros que resuelve una solicitud de indulto no es, en principio, dadas las características con las que está concebido en nuestro ordenamiento jurídico, un acto idóneo para trazar la dirección política que la Constitución asigna al Gobierno. Es verdad que puede responder a una determinada política criminal, la seguida por el que lo dicta, pero no tiene la entidad de los actos de orientación política que la Ley 50/1997 excluye expresamente del concepto de despacho ordinario de asuntos públicos". 
b) Ahora bien, ni esas consideraciones abstractas ni la conclusión general alcanzada se bastan por sí solas, aun cuando predeterminen el resultado y nos den una orientación global general, sino que el concreto indulto sujeto a examen ha de superar, además, un análisis particular, al menos para comprobar que no se trata de un caso excepcional respecto de la regla general antes sentada. En esta línea, el Tribunal Supremo destaca tres aspectos fundamentales: Por un lado, se trató de una resolución de indulto "que dejó inalterados los efectos de la Sentencia firme de la Sección Segunda de la Audiencia Provincial de Madrid que condenó al recurrente». Por otro, se trató de una denegación de indulto "que no ha mermado las facultades del nuevo Gobierno, que puede resolver lo que considere procedente sobre ese indulto si, en virtud de las normas legales que lo regulan, vuelve a ser sometido a su consideración", algo no descartable. También se valora, en fin, que "no se pronunció dicho Acuerdo sobre la solicitud del recurrente solamente, sino que también lo hizo, siempre en el mismo sentido denegatorio, sobre las de otros ciento cuarenta y ocho penados, siendo de advertir que la del recurrente, presentada el 25 de julio de 2003, llevaba el número de expediente 86 de ese año. Eso significa, no sólo que resolver sobre peticiones de indulto forma parte de la actividad normal del Consejo de Ministros, ya que los expedientes de indulto son numerosos, sino que difícilmente cabe distinguir en ese conjunto de decisiones denegatorias una actividad de orientación política como la que hemos dicho que nuestro ordenamiento jurídico excluye de la noción de despacho ordinario de los asuntos públicos. Desde luego, nada se aprecia en ese sentido del expediente y de lo que se ha alegado en el presente proceso". Y es que cualquiera que conozca la práctica forense sabe que la petición de un indulto, y la tramitación del mismo con emisión de informe del tribunal sentenciador, es tarea absolutamente habitual en cualquier juzgado de lo penal, por modesto que sea su número de asuntos, y también es sabido que el indulto se utiliza con frecuencia como medio de dilatar el cumplimiento de la pena, práctica que es especialmente frecuente en casos de delitos contra la seguridad del tráfico — pese a que en esa materia prácticamente no se concede ningún indulto por ningún Gobierno-, como medio de retrasar simplemente el cumplimiento de la pena de privación del derecho de conducir vehículos de motor y ciclomotores. Quizá no esté de más al hilo de esta idea reseñar que el nuevo Gobierno que tomó posesión con posterioridad a este período de permanencia en funciones se enfrentó a un amplio número de indultos pendientes, concretamente 5.089 (al terminar el año los expedientes que todavía se encontraban en fase de tramitación serían 11.450.), lo que da una buena medida del fenómeno al que nos enfrentamos y parece incidir en el dato de que aquel Gobierno cesante se limitó a dar curso ordinario a los indultos que normalmente correspondería aprobar en un Consejo de Ministros cualquiera siguiendo el orden correspondiente. 


\section{IV.4. OBSERVACIONES FINALES}

El Tribunal Supremo acaba de iniciar con estas dos sentencias una tarea indudablemente compleja, pero de enorme interés: la determinación, cabría hablar quizá de disección, del verdadero campo de acción de un Gobierno cesante.

La espita de este control judicial ahora abierta, que se irá desmenuzando casuísticamente, será difícil que se cierre, pues no parece aventurado considerar que una vez abierto este camino serán muchas las reclamaciones que puedan producirse con ocasión de las diferentes decisiones que pueda tomar un gobierno en este estado, especialmente en el caso de una prorogatio que no fuere meramente formal.

Aunque técnicamente incluso en este supuesto podría procederse a la anulación de determinados acuerdos, no en vano aunque coincidimos con Revenga en que hay supuestos en que cabe defender de que se "ensancha" el margen de maniobra de un Gobierno cesante por la perpetuación del nexo fiduciario $^{61}$ (de manera similar, López Guerra destaca que, "la situación del Gobierno cesante será muy distinta en supuestos en que se mantenga la misma mayoría en las Cámaras y se prevea una continuidad de orientación y dirección" $\left.{ }^{62}\right)$, lo cierto es que, como apuntamos supra, ello podría valer únicamente, y en su caso, para el oportuno control político, pues a estos efectos, y a partir de las sentencias comentadas, es claro que el único momento a tener en cuenta será la toma de posesión del nuevo gobierno como momento ad quem de la permanencia en funciones. Y, más allá de las previsiones respecto de la celebración de elecciones generales y la suspensión en este supuesto de las delegaciones legislativas concedidas, la Ley nada distingue.

Hubiera sido interesante también que el tema del indulto frente a cuya denegación se presentó el recurso finalmente desestimado, hubiera terminado llegando en amparo al Tribunal Constitucional (la alegación del recurrente artículo 24 CE en conexión con el 17 hubiera podido ser, quizá, una fórmula), en orden a cotejar la final resolución del caso y especialmente la posibilidad de que se hubiera llegado a plantear a partir de aquí una autocuestión de inconstitucionalidad respecto de la posibilidad de establecer o no limitaciones por parte del legislador — las del artículo 21 de la Ley del Gobierno- frente a la actuación de un Gobierno en este estado, cuestión sobre la que la doctrina no parece ponerse de acuerdo. Tanto durante la tramitación de dicha Ley como tras su aprobación fue esta una cuestión sobre la que existieron diferentes planteamientos que abundarían en una y otra línea.

Las sentencias aquí abordadas nos han permitido acercarnos a un tema que renace de manera intermitente al hilo de aquellos traspasos de poderes en

61 La formación del Gobierno en la Constitución Española de 1978, cit., p. 68.

62 "Gobierno en funciones", Enciclopedia Jurídica Básica, (Volumen II), Cívitas, Madrid, 1995, p. 3.266. 
que se produce o presume un cambio de tendencia política, pero que a partir de ahora, y con el precedente abierto, se habrá de extender sin duda a supuestos de prorogatio formal como hemos venido apuntando. La delimitación específica, casuística, del concepto del despacho ordinario de los asuntos públicos (discerniendo la esfera de la "duda posible "63) y de los otros dos escogidos por el legislador en aras de limitar la actuación de un Gobierno en este estado vendrá sin duda por las futuras resoluciones judiciales que seguramente habrán de dictarse al abordar presuntas "evasiones" ${ }^{64}$ de un Gobierno cesante.

Para cerrar estas breves notas no nos resistimos a recordar, como apuntó Aguiar de Luque, aunque sea una mera anécdota, que la famosa sentencia Marbury $v$ Madison que tantos quebraderos de cabeza dio a los constitucionalistas, salvadas las distancias, vino a resolver precisamente el problema planteado por un Ejecutivo en funciones. Dicha sentencia, como es sabido, analizó el problema de la firma por parte del Secretario de Estado del Presidente federalista J. Adams, J. Marshall, de numerosos nombramientos de jueces de ideas federalistas la noche anterior a que el Presidente T. Jefferson, tomara posesión de la Presidencia (durante la última semana del mandato presidencial, y en el seno de una complicada sucesión tras la victoria electoral republicana, se llegaron a nombrar hasta un total de cuarenta y ocho jueces). Entre estos nombramientos se incluía el de W. Marbury como juez de paz del Distrito Federal de Columbia, que fue el que dio origen a esta sentencia clave del constitucionalismo.

ABSTRACT. In this papers, the authors analyze two recent rulings of the Spanish Supreme Court about the performance of the outgoing and acting Government after the elections of March of 2004, rulings which were focused in the legitimacy and scope of competences of an acting Government. In the former ruling, the Supreme Court (Sixth Section of the Administrative Litigation Chamber) quashes the Government's decision of granting the extradition of a British citizen to the Italian authorities, on the understanding that this resolution exceeded clearly of the "ordinary conduct of the public matters", which would be one of the criteria used by the Act on Government (1997) in order to confine the lawful performance of an acting Government. The latter ruling of Supreme Court (Administrative Litigation Chamber, in full session), justly based upon the opposite consideration, rejected the appeal against other

63 JELLINEK, W., Gesetz, Gesetzesandwendung und Zweckmässigkeiteserwägungen, Scientia Verlag Aalen, 1964, pp. 37 y ss.

64 Se sirve de esta expresión, en la doctrina italiana, L. ELIA, apuntando la dificultad de admitir la mpugnación de la validez de los actos de un Gobierno dimisionario ante la autoridad judicial ordinaria o ante los órganos de la justicia administrativa, "Amministrazione ordinaria degli organi costituzionale», Enciclopedia del Diritto, (II), Giuffrè, Milano, 1958. 
resolution of that acting Government, the denial of a reprieve petition, understanding that this acting Government's decision fitted well in the legal standard "ordinary conduct of public affairs". In this second sentence, the Chamber establishes a doctrine which is absolutely contrary to the one of the first ruling, passed only some months before by the Sixth Section, overruling it. In the light of this crossroad, the authors of this paper examine the legal grounds of both rulings, as well as the dissenting and partly concurring opinions issued by some Justices to the ruling passed by the abovementioned Chamber in full session. 